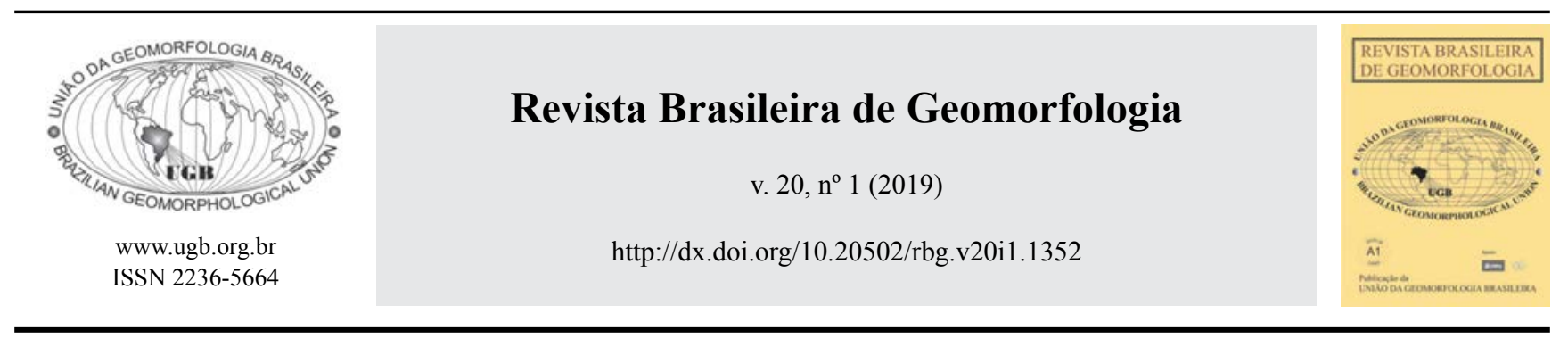

\title{
EROSÃO DE DUNAS SOB AÇÃO DE UM EVENTO EXTREMO DE ALTA ENERGIA DE ONDAS NA COSTA CENTRAL E SUL DO RIO GRANDE DO SUL, BRASIL
}

\section{DUNES EROSION UNDER AN EXTREME HIGH WAVE ENERGY EVENT ON THE CENTRAL AND SOUTHERN COAST OF RIO GRANDE DO SUL STATE, BRAZIL}

\author{
Ulisses Rocha de Oliveira \\ Instituto de Ciências Humanas e da Informação, Universidade Federal do Rio Grande \\ Avenida Itália, km 8, Rio Grande, Rio Grande do Sul. CEP: 96.201-900. Brasil \\ E-mail: ulisseslicke@yahoo.com.br
}

Rodrigo Silva Simões

Instituto de Ciências Humanas e da Informação, Universidade Federal do Rio Grande Avenida Itália, km 8, Rio Grande, Rio Grande do Sul. CEP: 96.201-900. Brasil

E-mail: rodrigosimoes@furg.br

Lauro Júlio Calliari

Instituto de Oceanografia, Universidade Federal do Rio Grande Avenida Itália, km 8, Rio Grande, Rio Grande do Sul. CEP: 96.201-900. Brasil E-mail:lcalliari@log.furg.br

Bruna Cavalcanti Gautério

Instituto de Ciências Humanas e da Informação, Universidade Federal do Rio Grande Avenida Itália, km 8, Rio Grande, Rio Grande do Sul. CEP: 96.201-900. Brasil

E-mail: gauteriobruna@gmail.com

\section{Informações sobre o Artigo}

Recebido (Received): 08/05/2018

Aceito (Accepted):

$16 / 11 / 2018$

Palavras-chave:

Erosão Costeira; Sistema Praia Duna; Monitoramento com Drone.

\section{Keywords:}

Coastal Erosion; Wave-Beach Dune Interaction; Coastal Monitoring.

\section{Resumo:}

Na costa oceânica do Rio Grande do Sul, muitos dos segmentos costeiros que estão em processo de erosão vem sendo urbanizados. O estudo do impacto de eventos de alta energia de onda em segmentos que apresentam dunas defrontantes a áreas urbanas é importante visando consolidar o estado da arte em relação a erosão costeira, e ao mesmo tempo para alertar sobre os problemas que podem ser ocasionados decorrentes da ocupação muito próxima do oceano. Este trabalho visou caracterizar a retração das dunas frontais como resultado da ação de um evento extremo de energia de onda ocorrido em outubro de 2016 na costa central e sul do Estado do Rio Grande do Sul, especificamente nos balneários Mostardense, Praia do Farol, balneário Praia do Mar Grosso, balneário Cassino, balneário Hermenegildo e Praia das Maravilhas. Para isto, foram analisadas fotografias aéreas verticais e oblíquas de alta resolução obtidas com auxílio de uma aeronave remotamente pilotada (drone), coletadas antes e após o evento, bem como dados meteo-oceanográficos. O evento ocorrido pode ser considerado como evento extremo de alta energia de onda. A altura 
significativa de onda (Hs) superou os $5 \mathrm{~m}$ próximo à costa e, em águas mais profundas, a altura significativa superou 6 $\mathrm{m}$, com altura máxima $(\mathrm{Hm})$ acima de $10 \mathrm{~m}$, valores não descritos nos últimos 40 anos nesta costa oceânica. $O$ período das ondas (Ts) foi de $15 \mathrm{~s}$. O referido evento gerou uma retração média das dunas frontais entre 4 e 21,8 m em média nos segmentos analisados e em certos locais houve mais de $40 \mathrm{~m}$ de retração da linha de costa. No entanto, houve variações nas taxas encontradas nos seis segmentos analisados. As maiores taxas ocorreram nas duas áreas mais ao norte (13,8 $\mathrm{m}$ em média em Mostardense e 21,8 m na Praia do Farol). As características naturais do local, com costa voltada para sul, barreira com tendência retrogradante e dunas preservadas, favoreceram a ação da alta energia de onda na costa. Nas áreas com barreira progradante e influência estuarina (Mar Grosso e Cassino), também houve retração das dunas frontais, tendo taxas de retração menores que Mostardense e Praia do Farol (9,6 m em Mar Grosso e $4 \mathrm{~m}$ na praia do Cassino). Especulase que nos balneários mais ao sul, as taxas ( $9,9 \mathrm{~m}$ no Hermenegildo e $8,8 \mathrm{~m}$ em Maravilhas) não tenham sido maiores pela presença de estruturas de contenção à erosão no Hermenegildo e turfas em Maravilhas, o que provavelmente contribuiu na redução da taxa de recuo das dunas frontais nestas áreas. A descrição deste processo erosivo intenso é importante para o planejamento da ocupação costeira no sentido de identificar que a variação da linha de costa, neste caso a retração do limite entre a praia e a duna frontal, não é um processo linear, mas sim em muitos casos uma resposta a eventos de alta energia de onda, sobretudo os chamados eventos extremos.

\begin{abstract}
:
On the oceanic coast of Rio Grande do Sul, many of the coastal segments that are in the process of erosion have been urbanized. The study of the impact of high wave energy events on segments presenting dunes facing urban areas is important in order to consolidate the state of the art in relation to coastal erosion, and at the same time to alert about the problems that can be occasioned by the occupation close to the ocean. This study aimed to characterize frontal dunes retreat as the result of an extreme high wave energy event, which took place in October 2016, in central and southern sectors of the Rio Grande do Sul State, specifically the beaches: Mostardense, Praia do Farol, Praia do Mar Grosso, Cassino, Hermenegildo e Maravilhas. For this, was analyzed vertical and oblique high resolution aerial photography remotely obtained with an unmanned aerial vehicle (drone) before and after the event, as well as, meteo-oceanographic data. This event can be considered as an extreme wave energy event. The significant wave height (Hs) exceeded $5 \mathrm{~m}$ close to the coast and in deepper waters the significant wave height exceeded $6 \mathrm{~m}$ with maximum height $(\mathrm{Hm})$ above $10 \mathrm{~m}$, such values were not described in the last 40 years on this oceanic coast. The wave period (Ts) was $15 \mathrm{~s}$. This storm generated a medium retraction of the frontal dunes between 4 and $21.8 \mathrm{~m}$ in most of the analyzed coastal segments. However, there were variations in the rates found in the six segments analyzed. The highest rates occurred in the two areas to the north (13.8 $\mathrm{m}$ in average in Mostardense and $21.8 \mathrm{~m}$ in Farol Beach). The natural characteristics of the site, with a south facing coast, and a barrier with a retrogradational tendency and preserved dunes, favored the action of high wave energy on the coast. In areas with a prograded barrier and estuarine influence (Mar Grosso and Cassino), there was also frontal dune retraction but with lower retraction rates than Mostardense and Farol Beach (9.6 m in Mar Grosso and $4 \mathrm{~m}$ in Cassino beach). It is speculated that in the southern beaches, the rates (9.9 $\mathrm{m}$ in Hermenegildo and $8.8 \mathrm{~m}$ in Maravilhas) were not higher due to the presence of erosion containment structures in Hermenegildo and peat outcrops in Maravilhas, which probably contributed to the reduction of the rate of frontal dunes retreat. The description of this intense erosive process is important for the planning of coastal occupation in order to identify that coastline changes, in this case the retraction of the boundary between the beach and the frontal dune, is not a linear process, but in many cases a response to high wave energy events, especially so-called extreme events.
\end{abstract}

\section{Introdução}

A orla oceânica, ou marítima, é uma estreita faixa de contato da terra com o mar (BRASIL, 2004). Em orlas compostas de praias arenosas (e dunas frontais), a ação de processos costeiros se faz sentir de forma mais acentuada e potencialmente mais crítica, à medida que efeitos erosivos e/ou deposicionais podem alterar sensivelmente a configuração da linha de costa (MUEHE, 2001).
Atualmente, muitos segmentos de praias com presença de dunas frontais vêm sofrendo erosão. As causas da erosão costeira são complexas e envolvem muitas variáveis (SOUZA et al., 2005). Segundo estes autores, se analisarmos a dinâmica a médio e longo período, a variação do nível relativo do mar, o déficit sedimentar, alterações no padrão de correntes, ou mesmo algumas ações humanas sobre certo segmento, podem estar re- 
lacionadas à causa de processos erosivos. Já em curto período, na escala de eventos, podemos destacar a ação dos eventos de alta energia de onda, popularmente chamados de "ressacas do mar" (MELO et al., 2016). Estes eventos potencializam processos de erosão costeira, retirando sedimentos da praia subaérea e por vezes das dunas frontais. Segundo Dolan e Davis (1992), as tempestades costeiras podem ser desde fracas a moderadas até severas e extremas, quando as características energéticas máximas regionais são alcançadas ou até superadas.

Calliari e Klein (1993) caracterizaram processos erosivos na costa oceânica sul do Rio Grande do Sul, sobretudo, após a passagem de frentes frias e/ou ciclones extratropicais. Segundo Tozzi (1999) observam-se perfis côncavos após as tempestades e perfis convexos durante os longos períodos de menor regime hidrodinâmico. No entanto, o volume subaéreo varia muito em curtos episódios, o que representa uma moderada e por vezes alta, susceptibilidade a erosão. De acordo com sua magnitude, estes eventos podem erodir as dunas frontais, formando escarpas dunares que posteriormente podem ou não se recompor, dependendo do aporte sedimentar e da própria dinâmica costeira. Barletta eCalliari (2002) identificaram a intensidade de tempestades que ocorrem na costa do Rio Grande do Sul, relacionando estas à variação do estoque sedimentar subaéreo das praias. Já Machado et al. (2010) relacionaram para esta costa a ação dos eventos mais severos e a erosão costeira.

Na costa oceânica do Rio Grande do Sul, muitos dos segmentos costeiros que estão em processo de erosão são ou vem sendo urbanizados. Nestes locais, o impacto de eventos de alta energia de onda, sobretudo os chamados eventos extremos, geram a erosão das dunas frontais e danos para ocupações situadas junto à praia (ESTEVES et al., 2000, ESTEVES, 2004). O objetivo deste trabalho é caracterizar o impacto de um evento extremo de alta energia de onda, ocorrido em outubro de 2016, sobre as dunas frontais em segmentos urbanizados (balneários), situados no litoral central e sul do Estado do Rio Grande do Sul, especificamente os balneários Mostardense, Praia do Farol, balneário Praia do Mar Grosso, balneário Cassino, balneário Hermenegildo e Praia das Maravilhas (Figura 1). Para isto, foram analisadas fotografias aéreas de alta resolução capturadas com auxílio de uma aeronave não tripulada (drone), obtidas antes e após o evento. Busca-se, além de caracterizar o impacto do evento na retração das dunas frontais, identificar diferenças entre as localidades analisadas, discutindo as forçantes naturais e/ou antrópicas correlacionadas.

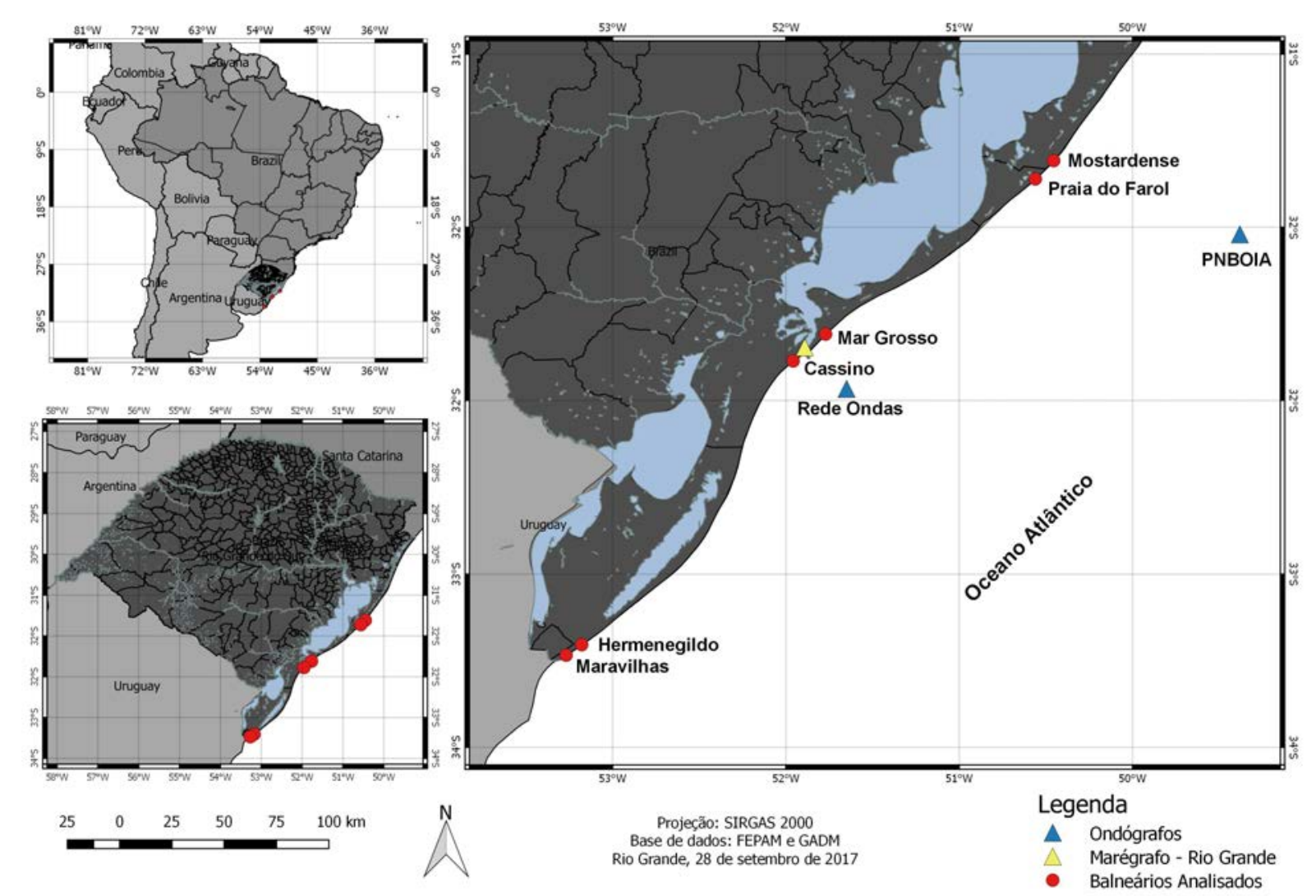

Figura 1 - Mapa de localização da área de estudo, destacando os balneários analisados e os locais onde foram obtidos dados oceanográficos do evento (ondas e marés). 


\section{Área de Estudo}

A costa do Rio Grande do Sul (RS) se estende desde a desembocadura do Rio Mampituba localizado em Torres, até a desembocadura do Arroio Chuí na fronteira entre Brasil e Uruguai, apresentando uma orientação geral Nordeste-Sudoeste. Apresenta sucessivas barreiras costeiras intercaladas por lagoas costeiras (VILLWOCK e TOMAZELLI, 1995). A barreira holocênica apresenta variações em suas características, com segmentos transgressivos, regressivos e relativamente estáveis (DILLENBURG et al., 2000; DILLENBURG et al., 2005; DILLENBURG et al., 2009), os quais se dispõem em porções de linha de costa levemente convexas e côncavas. Na parte oceânica apresenta praias arenosas compostas predominantemente de areia fina e com dunas frontais na retaguarda (CALLIARI et al., 2005; CALLIARI e TOLDO JR, 2016). As praias arenosas apresentam homogeneidades em suas características morfodinâmicas, como presença de sedimentos arenosos e os processos costeiros a que estão sujeitas, mas também heterogeneidades, tais como na declividade, no diâmetro médio dos sedimentos arenosos e na orientação da linha de costa (PEREIRA et al., 2010).

O limite superior da praia é caracterizado pela presença das dunas frontais (UGRI, 2004; CALLIARI et al., 2005), sendo estas interrompidas por pequenas redes de drenagem (PEREIRA DA SILVA, 1998) e pela presença de urbanização (ESTEVES, 2004). A urbanização da costa oceânica do Rio Grande do Sul foi introduzida em um ambiente de alta mobilidade sedimentar, sobretudo para utilização ocasional como segunda residência (MORAES, 2007), majoritariamente ocupada na temporada de verão. Atualmente a ocupação é mais desenvolvida no litoral norte entre Torres e Tramandaí (STROAHECKER, 2007) e na praia do Cassino, que absorve boa parte do contingente de pessoas da metade sul do Estado durante as temporadas de veraneio. Nas demais localidades da costa central e sul do Estado, a urbanização defronte ao mar é pontual (ESTEVES, 2004), remetendo a trechos de até $2 \mathrm{~km}$ de orla urbanizada. Questões locais relacionadas à falta de um planejamento mais adequado respeitando as feições geomorfológicas locais são ocorrentes, refletindo em problemas ambientais nos balneários do Hermenegildo
(ESTEVES et al., 2000), Mostardense e Praia do Farol (SIMÕES, 2015; SIMÕES, 2018) e balneário Mar Grosso (CUNHA, 2013). Nestes locais a ocupação foi introduzida em meio a dunas móveis próximo da linha de costa.

A figura 2 demonstra que as localidades analisadas estão sob características geomorfológicas distintas. Os balneários Mostardense (1) e Praia do Farol (2) encontram-se mais ao norte da área de estudo, em um trecho marcado por campos de dunas transgressivas num segmento costeiro convexo (Figura 2 - II). Mar Grosso (3) e Cassino (4) situam-se nas adjacências da desembocadura da Lagoa dos Patos, onde a barreira holocênica é do tipo progradante num segmento côncavo da costa (Figura 2 - III). Hermenegildo (5) e Maravilhas (6) situam-se no extremo sul do Estado (Figura 2 - IV), local situado ao sul de uma projeção costeira onde a barreira IV vem sendo suprimida (LIMA, 2008) e o mar encontra a barreira pleistocênica no segmento mais austral do litoral brasileiro (CARON, 2014).

O balneário Mostardense situa-se no município de Mostardas ( $31^{\circ} 09^{\prime} 05^{\prime}$ 'S e $50^{\circ} 48^{\prime} 38^{\prime \prime} \mathrm{W}$ ), em um segmento de costa bastante instável do ponto de vista sedimentar (SIMÕES, 2018), tanto pela dinâmica imposta pelo oceano quanto pela ação eólica. A praia apresenta características intermediárias a dissipativas (PEREIRA et al., 2010) com predomínio de bancos longitudinais submersos e feições rítmicas como cúspides praiais. Dunas frontais ocorrem entre a área urbana e a praia, e campos de dunas transgressivas ocorrem na retaguarda. A localidade apresenta uma orla urbanizada de cerca de $2 \mathrm{~km}$, havendo sangradouros naturais nas extremidades, e drenagens urbanas e arruamentos na orla do balneário, as quais fragmentam as dunas frontais. As dunas frontais junto ao balneário apresentam menor largura na orla urbana, sobretudo no setor centro-sul do balneário (SIMÕES, 2018).

O balneário Praia do Farol ( $31^{\circ} 14^{\prime} 53^{\prime \prime} \mathrm{S}$; $50^{\circ} 54^{\prime} 26^{\prime \prime} \mathrm{W}$ ), situa-se cerca de $14 \mathrm{~km}$ ao sul do balneário Mostardense, no município de Tavares. Assim como no balneário Mostardense, este sítio urbano está em um ambiente altamente instável do ponto de vista sedimentar, com praias dissipativas a intermediárias, dunas frontais e transgressivas e canais sangradouros (SIMÕES, 2015). A costa deste segmento apresenta taxas erosivas, sobretudo ao sul dessa área (SPERANSKI 


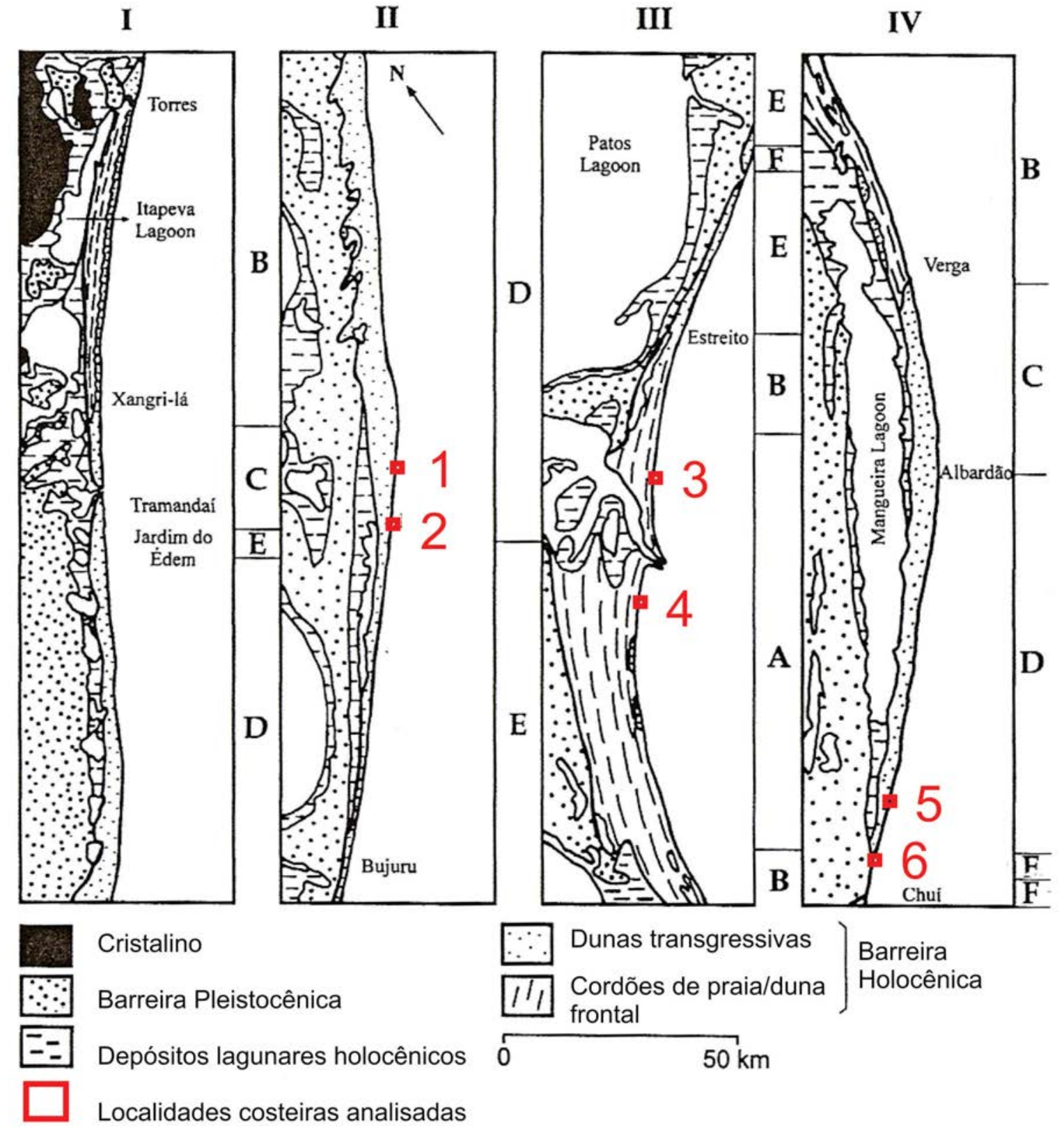

Figura 2 - Mapa geomorfológico compartimentado da barreira holocênica do Rio Grande do Sul segundo Dillenburg et al., 2000 (com legenda editada), destacando a localização das seis localidades costeiras analisadas: (1) Mostardense, (2) Praia do Farol, (3) Mar Grosso, (4) Cassino, (5) Hermenegildo e (6) Maravilhas.

\section{e CALLIARI, 2006).}

O balneário Praia do Mar Grosso localiza-se a pouco mais de $10 \mathrm{~km}$ ao norte da desembocadura da Lagoa dos Patos (32॰03'12”'S; 51 59 '36”W). Caracteriza-se por alguns núcleos urbanos num trecho de cerca de $2,5 \mathrm{~km}$ de costa. Nesta porção da planície costeira, ocorrem pastagens na retaguarda das dunas frontais, sem a presença de campos de dunas transgressivas, como nas localidades analisadas mais ao norte da área de estudo. A praia tem menor declividade do que as praias junto ao Farol de Mostardas (Praia do Farol) e ao balneário Mostardense (PEREIRA et al., 2010), havendo menor presença de cúspides e megacúspides praiais, mas também apresenta predomínio de bancos e cavas longitudinais segundo a classificação de Wright e Short (1984). As dunas frontais ao balneário passaram recentemente por regeneração induzida por ações antrópicas no início dos anos 2000 (CUNHA, 2013).

O balneário Cassino (32॰11'14”'S; 529'21'”) é a maior aglomeração urbana defrontante ao oceano 
da costa central e sul do Rio Grande do Sul. É também o que apresenta a mais larga faixa de areia entre a orla urbana e o oceano (sistema praia duna), sendo também a praia com menor declividade dentre as analisadas e a que apresenta granulometria mais fina (PEREIRA et al., 2010), recebendo, por vezes, depósitos de lama fluída (MARTINS et al., 2003). Outra característica peculiar é seu maior embaiamento se comparado com a maioria das praias da costa oceânica do Rio Grande do Sul, mais retilíneas quando analisadas em planta. O sistema dunar defrontante a área urbana é preservado, devido principalmente da implantação, na década de 1990, de um plano de manejo para conservação das dunas realizado pelo Núcleo de Educação e Monitoramento Ambiental (NEMA) em conjunto com a Prefeitura Municipal (COSTA, 2013). A praia apresenta na retaguarda uma barreira progradante, sendo esta formada devido ao aporte de sedimentos proveniente do sul da planície costeira, por deriva litorânea (DILLENBURG et al., 2000; DILLENBURG et al., 2009) e o aporte proveniente da desembocadura da Lagoa dos Patos (MILANA et al., 2016).

O balneário do Hermenegildo (3339'59' S; $\left.53^{\circ} 15^{\prime} 35^{\prime \prime} \mathrm{W}\right)$ tem histórico relacionado com a erosão costeira (KOERNER et al., 2013, ALBUQUERQUE et al., 2013). Estruturas de contenção a erosão já são colocadas há algumas décadas, e sofrem incremento a cada ano (ESTEVES et al., 2000; OLIVEIRA e KOERNER, 2015). A praia varia de dissipativa a intermediária (PEREIRA et al., 2007). Dunas transgressivas, que já foram bastante instáveis nas adjacências e mesmo próximo da área urbana, foram estabilizadas por ação humana (KOERNER, 2009), enquanto que as dunas frontais vêm sendo suprimidas entre a área urbana e a praia (OLIVEIRA et al., 2018).

O balneário Praia de Maravilhas (3343'17's; $53^{\circ} 20^{\prime} 30^{\prime \prime} \mathrm{W}$ ), situado $8 \mathrm{~km}$ ao sul de Hermenegildo e $3 \mathrm{~km}$ ao norte da Barra do Chuí, é adjacente a uma praia com características morfodinâmicas semelhantes à do Hermenegildo, mas num segmento de praia onde afloram atualmente depósitos de lama consolidada e turfa (BUCHMANN et al., 1998). Segundo a observação do mapeamento geológico encontrado em Rosa et al., (2017) e observações in loco, ao sul desta área já houve supressão da barreira holocênica e depósitos pleistocênicos afloram na praia. As turfas e os depósitos lagunares de idade holocênica na faixa de praia indicam retrogradação da barreira em escala geológica. Mesmo assim, há presença de urbanização junto a praia. Esta se iniciou na metade do século passado e se expandiu para áreas muito próximas do oceano.

\section{Materiais e Métodos}

Para caracterizar o impacto do evento de alta energia de onda na costa, fotografias aéreas verticais e oblíquas da orla dos balneários foram adquiridas in loco usando uma aeronave remotamente pilotada, Drone DJI ${ }^{\circledR}$ Phantom 3 Professional, nas seguintes datas: Balneário Mostardense (10/10/2016 e 05/11/2016); Praia do Farol (10/10/2016 e 06/12/2016); setor norte do balneário Mar Grosso (09/07/2016 e 09/12/2016); setor junto a passarela sobre as dunas no balneário Cassino (22/09/2016 e 29/10/2016); setor norte do balneário do Hermenegildo (27/09/2017 e 19/11/2016) e balneário das Maravilhas (26/09/2016 e 18/11/2016). No Mar Grosso apenas o setor norte foi analisado devido a uma falha em uma das fotografias capturadas. Já no balneário Cassino, pela dimensão da orla urbana, que supera os $6 \mathrm{~km}$, as fotografias aéreas verticais propositalmente foram captadas apenas de um pequeno segmento onde há uma passarela sobre as dunas, o que favoreceu o georreferenciamento. No balneário do Hermenegildo optou-se por analisar apenas o segmento norte, pois este é o único que ainda apresenta dunas frontais no perímetro urbano. Salienta-se que todo o conjunto de fotografias aéreas analisado, contempla um período anterior e um posterior ao ciclone ocorrido em outubro de 2016.

Em gabinete, as fotografias aéreas verticais foram processadas no software Agisoft ${ }^{\circledR}$ Photoscan gerando mosaicos de fotografias aéreas. $\mathrm{O}$ erro médio quadrático (RMS) do registro dos mosaicos, foi inferior a 1 pixel $(0,16 \mathrm{~m}$ no Mostardense e $0,08 \mathrm{~m}$ nas demais localidades) em todos os segmentos analisados. Segundo Boak e Turner (2005) há diversos indicadores que podem ser utilizados para determinar a variação da linha de costa, dentre os quais podemos destacar: a linha de vegetação dunar, a linha de eventos de tempestade e a escarpa do limite superior da praia, sendo este último, o indicador utilizado neste trabalho. Deste modo, o limite superior da praia foi considerado como o limite entre o pós-praia e a base da duna frontal, embora eventualmente ocorram depósitos eólicos sobre a faixa de praia e marinho-praiais à retroterra.

O limite praia duna foi vetorizado no software QGIS ${ }^{\circledR}$ na escala 1:500. Ressalta-se que a vetorização foi realizada analisando conjuntamente as fotografias oblíquas, o que possibilitou identificar mais precisamente o limite entre a praia e a duna, fato por vezes, difícil 
sem esse auxílio. A partir disso, foi estimada a variação da linha de costa para cada recorte espacial através do método do polígono de mudança (SMITH e CROWLEY, 2012). Este método consiste na criação de polígonos com três faces idênticas e uma face diferente, correspondente a linha de costa, permitindo a realização de precisos cálculos de variação de área dos polígonos e então de variação média de linha de costa. Deste modo foi calculada a diferença entre o polígono anterior e o posterior a passagem do ciclone para cada segmento de costa analisado, obtendo-se a variação da área de dunas erodida $\left(\mathrm{m}^{2}\right)$ e o valor médio de variação de linha de costa (m). Salienta-se que os polígonos não foram plotados nos mosaicos para manter ao máximo as características do sistema praia duna, optando-se por plotar apenas as linhas do limite praia duna. As fotografias aéreas oblíquas inseridas no texto tiveram um caráter qualitativo no sentido de ilustrar ou elucidar alguns processos observados e medidos.

Para caracterização do evento extremo de alta energia de onda, primeiramente foram adquiridas imagens GOES WV Realce 1 na página www.cptec. inpe.br visando apenas a demonstração do evento de forma qualitativa. Dados de onda foram medidos por dois ondógrafos direcionais, um situado em águas mais rasas, próximo à área de estudo, e outro numa área mais afastada da costa. $\mathrm{O}$ equipamento situado em águas mais rasas $(\sim 15 \mathrm{~m})$ é do Projeto Rede Ondas, denominado Boia Praia do Cassino, dada sua localização, estando a cerca de $10 \mathrm{~km}$ da costa na altura do balneário Cassino (30²0’23”S, 51 $53^{\circ} 53^{\prime}$ 'W). Os dados deste equipamento estão disponíveis em www.redeondas. com.br provendo informações de altura significativa, período e direção de onda. Os dados de altura máxima e ondulações secundárias não foram disponibilizados no site. O segundo equipamento que forneceu dados foi do Programa PNBOIA. Este se situa a $100 \mathrm{~km}$ da costa na altura de Mostardas $\left(31^{\circ} 31^{\prime} \mathrm{S}, 49^{\circ} 48^{\prime} \mathrm{W}\right)$, próximos da quebra da plataforma continental, sendo chamado de Boia Rio Grande. Estes dados estão disponíveis em www.mar.mil.br. Para este trabalho foram analisados principalmente os dados de altura significativa e altura máxima do ondógrafo situado em águas profundas. Dados de maré foram obtidos do Banco Nacional de Dados Oceanográficos e correspondem às medições horárias realizadas na área da Estação dos Práticos da Barra de Rio Grande (Praticagem), situado nas proximidades da entrada da Lagoa dos Patos (32 $\left.2^{\circ} \mathrm{S}, 52^{\circ} 6^{\prime} \mathrm{W}\right)$.

\section{Resultados e Discussão}

\section{$O$ evento extremo de alta energia de onda}

Em 27 de outubro de 2016 formou-se um centro de baixa pressão atmosférica na forma de um ciclone na costa sudeste da América do Sul, ao sul do Trópico de Capricórnio, formando uma nuvem vírgula seguido de vórtice sobre o Atlântico Sul próximo à costa na altura do Uruguai e Rio Grande do Sul (Figura 3), deslocando-se para leste. Observa-se na figura um rápido avanço da frente do vórtice interno em direção a norte, paralelo a linha de costa, entre as 16 e as 22 horas do dia 27 de outubro de 2016.

Na planície costeira do Rio Grande do Sul, a Companhia Estadual de Energia Elétrica (CEEE) decretou situação de emergência decorrente deste ciclone extratropical, o qual, segundo a mesma, provocou rajadas de ventos (variando de SW a S) moderados a fortes (de cerca de $100 \mathrm{~km} / \mathrm{h}$ ) durante várias horas seguidas sobre as regiões da campanha, sul, leste, parte do centro e do nordeste do Estado do Rio Grande do Sul (CEEE, 2016). Houve queda de árvores, destelhamentos e falta de energia elétrica. $\mathrm{Na}$ costa, houve forte agitação marítima e relatos de inundação e erosão costeira. A figura 4 identifica parâmetros oceanográficos durante a passagem do evento de outubro de 2016. O gráfico compreende o período entre 24/10/2016 e 31/10/2016 sendo que o pico do evento iniciou no dia 27 de outubro e se estendeu até o dia 28.

A figura 4 mostra que o evento foi precedido por uma pré-frontal que gerou ondas de ENE, de comum ocorrência antes da entrada de frentes frias no sul do Brasil. Os dados do ondógrafo do PNBOIA (Boia Rio Grande) situado em águas mais profundas, a $100 \mathrm{~km} \mathrm{da}$ costa na altura do balneário Mostardense, mostram que a altura significativa ficou acima de $6 \mathrm{~m}$ durante cerca de $48 \mathrm{~h}$. No auge do evento, na madrugada do dia 28 de outubro, a altura significativa chegou a $9,5 \mathrm{~m}$. As ondas tiveram altura máxima de cerca de $10 \mathrm{~m}$ durante $72 \mathrm{~h}$, chegando a picos de até 14,8 m (Figura 4a). No ondógrafo do Rede Ondas (Boia Praia do Cassino) situado em águas mais rasas, a $10 \mathrm{~km}$ da costa, num segmento com plataforma continental rasa e larga, a altura significativa das ondas chegou a 5,1 m (Figura 4b). Este equipamento registrou altura significativa superior a $3 \mathrm{~m}$ durante cerca de $48 \mathrm{~h}$. O período da ondulação (Figura 4d) foi de cerca de $15 \mathrm{~s}$, elevado para o padrão regional, que segundo Romeu et al., (2012), é em torno de 10 a 13 s para ondulações de S e SE, permanecendo neste caso de estudo, elevado por mais de 72 horas a partir da entrada das ondas de tempestade. 


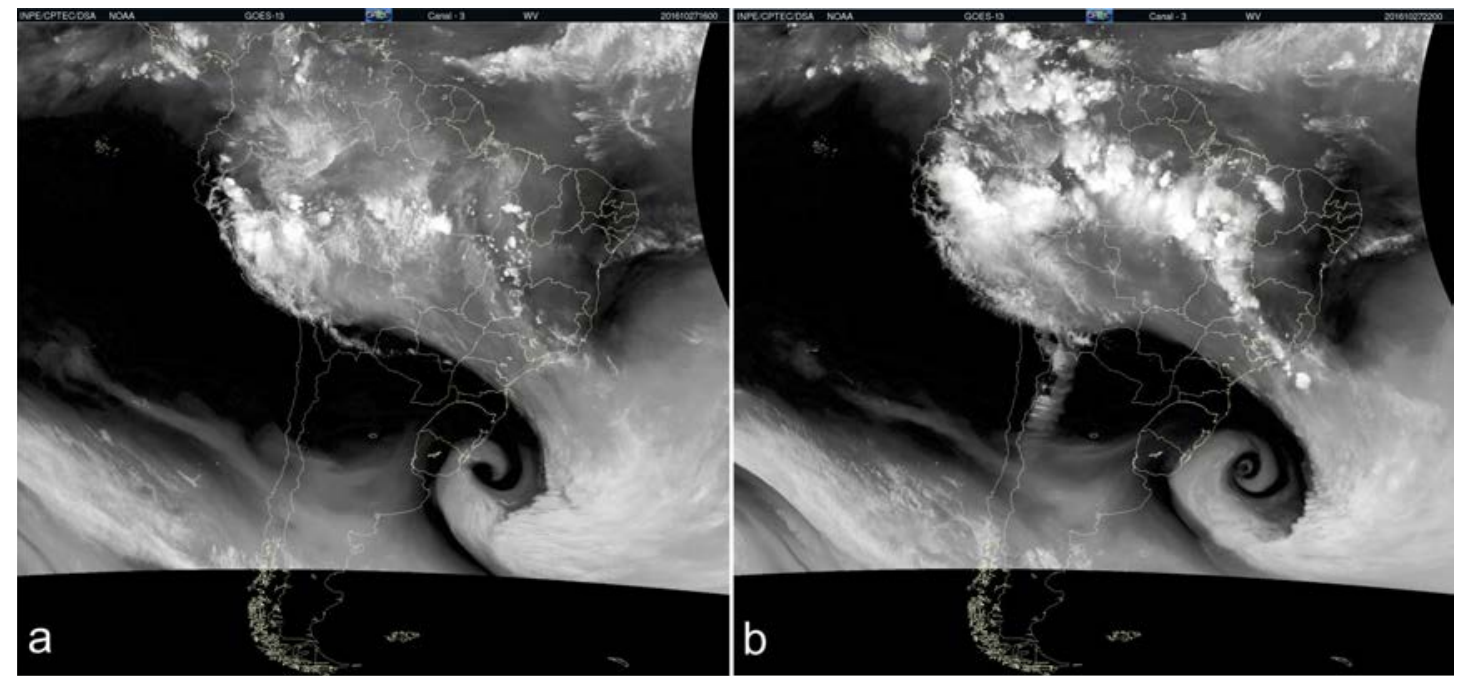

Figura 3 - Imagens GOES WV Realce 1 do ciclone extratropical em 27 de outubro de 2016 as 16 horas (a) e as 22 horas (b). Fonte: CPTEC.INPE.

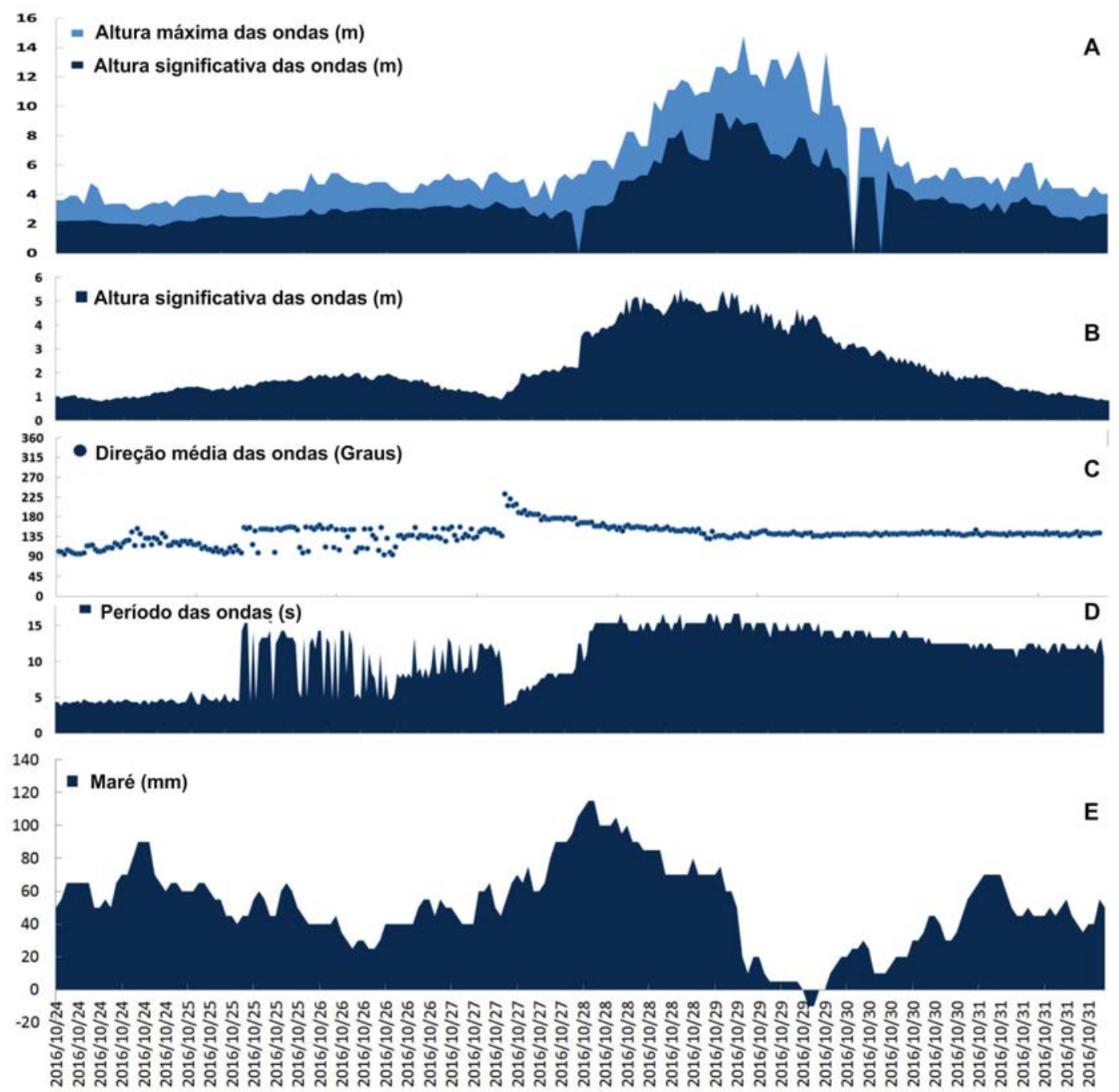

Figura 4 - Gráficos com parâmetros hidrodinâmicos costeiros entre 24/10/2016 e 31/10/2016, caracterizando: (a) Altura máxima e significativa das ondas medidas pelo ondógrafo do PNBOIA, localizado ao largo do balneário Mostardense, a $100 \mathrm{~km} \mathrm{da} \mathrm{costa;} \mathrm{(b,} \mathrm{c,} \mathrm{d)}$ Altura significativa, direção média e periodo das ondas medidas pelo ondógrafo do Rede Ondas, localizado ao largo do balneário Cassino, a 10 km da costa; (e) Maré, em milimetros, medida pela Praticagem do Porto do Rio Grande no canal de acesso ao Porto. 
Houve uma sutil mudança da direção das ondas a partir do início da tarde do dia 27, que proporcionou que as ondas, que já estavam aumentando em altura ao largo da costa com direção SW, passassem a incidir na costa na direção S (Figura 4c). As ondas cresceram abruptamente junto a costa, fato demonstrado nos dados do ondógrafo do Rede Ondas, situado em águas mais rasas, passando de menos de $2 \mathrm{~m}$ na tarde do dia 27, para mais $4 \mathrm{~m}$ na madrugada do dia 28 , chegando a $5 \mathrm{~m}$ ao longo do dia 28 de outubro. Este fato pode ter sido relevante para a erosão diagnosticada, pois as ondas iniciaram na ocasião seu poder destrutivo nas horas iniciais do evento, segundo relatos de pessoas que presenciaram o evento nos locais analisados, consultados por entrevistas livres pelos autores. Já no ondógrafo do PNBOIA as ondas subiram mais gradativamente. A variação na direção das ondas (de SW para S) e o expressivo incremento na sua altura foi acompanhada por uma subida no nível da maré, provavelmente potenciali- zou com que as ondas avançassem significativamente em direção as dunas. A sobre-elevação da maré alcançou mais de meio metro no canal de acesso a Lagoa dos Patos no início da madrugada do dia 28 (Figura 4e), havendo forte queda no nível da maré na madrugada do dia 29.

Nos locais analisados, a subida do nível de maré durante o evento não foi medida in loco. No entanto, o evento foi fotografado e filmado, sendo postado nas principais redes sociais por diversas pessoas que o presenciaram (Figura 5a, $5 b)$. Na figura 5 foram selecionadas imagens de distintos locais dentro do contexto da área de estudo durante o evento, destacando a altura das ondas e a reflexão do espraiamento no balneário do Hermenegildo e a sobre-elevação da maré nos balneários Cassino e Mostardense (Figura 5c, 5d). Vianna (2018) identificou valores superiores a $2 \mathrm{~m}$ de sobre-elevação da maré neste período em segmentos da orla oceânica ao norte da área de estudo, baseado em marcas em postes e edificações.
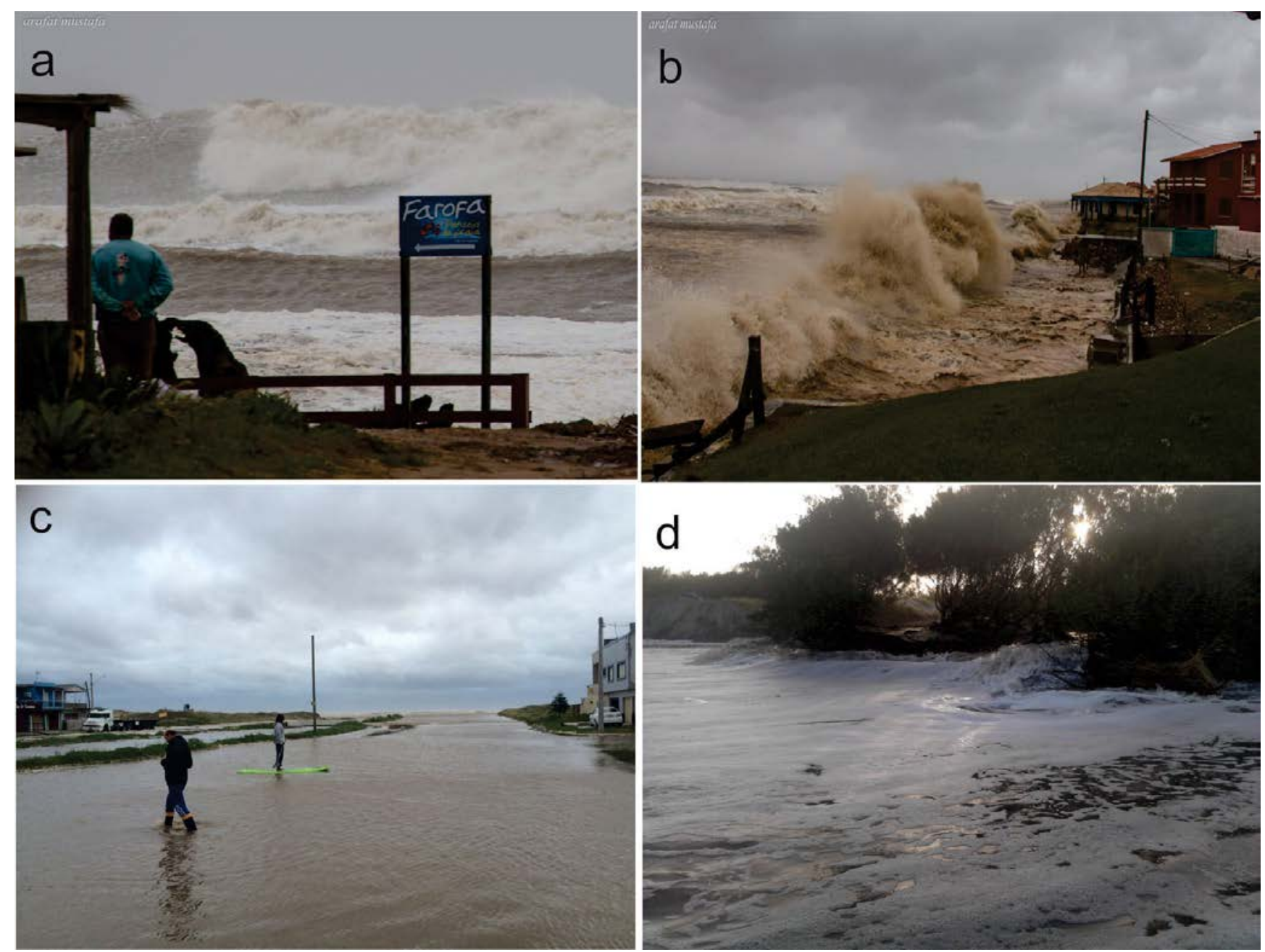

Figura 5 - a) Mar com altos níveis de maré e altura de onda no balneário do Hermenegildo em 27/10/2016. Foto: Arafat Mustafa. b) Reflexão do espraiamento (backswash) no balneário do Hermenegildo em 27/10/2016. Foto: Arafat Mustafa. c) Inundação costeira no balneário Cassino em 27/10/2016. Foto: Coautor. d) Sobrelevação da maré no balneário Mostardense em 28/10/2016. Foto: Morador Local. 
Os valores e cenas demonstrados nas Figuras 4 e 5, sobretudo da altura e energia de onda e sobre-elevação da maré medida, foram significativos para esta costa, que é, segundo Calliari et al., (1998), acostumada a receber impacto de eventos de alta energia de onda.

Barletta e Calliari (2002), analisaram dados de alta energia de onda entre 1996 e 1999 para a costa do Rio Grande do Sul. Os autores se basearam em dados medidos por ondógrafo, aplicando a estes a metodologia de Dolan e Davis (1992), que relaciona a altura e a duração das ondas, e dados de perfis de praia para caracterizar a energia de onda na costa. Nos 744 dias analisados foram identificados 77 dias com ondas superiores a 2 $\mathrm{m}$ e apenas 1 dia considerado como evento de energia extrema, justamente em abril de 1999, quando ocorreu severa erosão na costa e destruição de propriedades no balneário do Hermenegildo, caracterizados em Esteves et al., (2000). O evento analisado no presente trabalho foi mais intenso que o de abril de 1999, tanto em altura quanto em tempo de permanência das ondas, embora em 1999 tenha ocorrido mais danos por conta da menor resistência das estruturas de contenção inseridas no local se comparadas as colocadas atualmente, conforme aponta o estudo de Oliveira e Koerner (2015).

Melo et al., (2010), através de dados do modelo WW3 (Wavewatch III), caracterizou 40 condições de extrema energia de ondas, com altura significativa acima de 6 m (Hs > 6 m), entre 1979 e 2008, em águas profundas, ao largo da costa oceânica do Rio Grande do Sul. Segundo Melo et al., (2010), o evento mais significativo em 30 anos de dados, ocorreu em junho de $2006 \mathrm{com} 8,79 \mathrm{~m}$ de altura significativa $(\mathrm{Hs})$ e período (Tp) de 14,68 s. Com base nos mesmos autores, o segundo evento mais severo analisado ocorreu em maio de 2003, onde os dados do modelo indicaram Hs $=8,7 \mathrm{~m} \mathrm{e} \mathrm{Tp}=16,2 \mathrm{~s}$. Segundo Melo et al., (2010), este evento de 2003 foi medido por um ondógrafo situado em águas profundas, que registrou $\mathrm{Hs}=6,9 \mathrm{~m} \mathrm{e} \mathrm{Tp}=16$ $\mathrm{s}$, valores $26 \%$ menores que o estimado pelo modelo. Já em setembro de 2001, ocorreu o maior valor obtido por um ondógrafo $(\mathrm{Hs}=7,5 \mathrm{~m})$, sendo este subestimado pelo modelo WW3, mostrando limitações de análise. O evento de abril de 1999, bastante destrutivo na costa (ESTEVES et al., 2000), teve altura significativa de 6,08 m em águas profundas, segundo dados do modelo WW3. Neste evento de outubro de 2016, as ondas medidas por um ondógrafo, situado também próximo ao limite da plataforma continental ao largo da costa do RS, foi de
9,5 $\mathrm{m}$. Este valor foi quase $1 \mathrm{~m}$ maior que o maior dado de modelo desta série de 30 anos de dados e cerca de 2 $\mathrm{m}$ maior que o maior valor registrado por um ondógrafo, podendo-se supor ter sido o mais intenso dos últimos 40 anos ao longo da costa oceânica do Rio Grande do Sul, visto que entre 2008 e 2016, após a série analisada por Melo et al., (2010), não tenha sido descrito nem observado outro evento com características parecidas.

O impacto do referido evento na erosão das dunas frontais nos locais analisados foi ocasionado principalmente pelas ondas de tempestade na costa, conforme mostram as figuras $3 \mathrm{e} 4$. Flather (2001) apud Melo et al. (2016) define que as ondas de tempestade são mudanças no nível da água geradas pelo forçamento atmosférico, especificamente pelo arrasto do vento na superfície do mar e por variações na pressão atmosférica da superfície associada às tempestades. Segundo Melo et al., (2010), os eventos extremos de agitação marítima podem não corresponder necessariamente aos casos extremos ocorridos na costa (ressacas), sendo o motivo principal relacionado à direção das ondas. Para Melo et al. (2016) os episódios de erosão costeira severa a curto prazo e/ou inundação costeira são, geralmente, devido à ocorrência simultânea de um nível elevado do mar mais um evento de alta energia de onda, ou "ressaca do mar", termo que para estes autores deve ser usado exclusivamente para identificar eventos de ondas "grandes" na costa usando a altura significativa da onda (Hs) como parâmetro de medição. No evento de 27/28 de outubro de 2016 a altura significativa de ondas superou os $6 \mathrm{~m}$ em águas mais profundas e os $5 \mathrm{~m}$ em águas rasas.

Em relação aos impactos na erosão das dunas frontais relacionados por outros eventos durante o período entre as fotografias aéreas analisadas, ressalta-se que no ano de 2016 um segmento da área de estudo (balneário Mostardense) foi monitorado mensalmente com fotografias aéreas de drone, somados a dados de onda e vento (SIMÕES, 2018). Estas medições possibilitaram avaliar que nenhum outro evento teve tamanha magnitude para gerar significativas alterações na linha de costa (limite praia duna) do litoral central e sul do Rio Grande do Sul, podendo-se então atribuir o recuo das dunas frontais no período entre as coletas quase que em sua totalidade ao ciclone de 27 de outubro. No entanto, mesmo atribuindo a retração das dunas caracterizadas no presente estudo em grande parte ao evento de 27 de outubro de 2016, ressalta-se que uma sequência de tempestades de menor energia ocorreu 
anteriormente, durante o outono-inverno-primavera de 2016, conforme relatou Simões (2018) para o balneário Mostardense. Isto pode ter promovido, conforme Dolan e Davis (1992), a geração de uma morfologia erosiva de praia, com erosão da face praial, redução da largura da berma da praia e aumento do gradiente do fundo marinho, favorecendo o espraiamento da onda até a da base da duna frontal durante o evento analisado.

Os resultados mostram que as taxas de erosão não foram iguais nas diferentes áreas analisadas, conforme demonstrado quantitativamente na Tabela 1. Estas áreas, a princípio, estiveram sujeitas aos mesmos processos costeiros (ondas, correntes e marés), podendo ter ocorrido alguma variação decorrentes da posição do evento extremo na costa e no seu deslocamento, mas sobretudo podem retratar distintas características geomorfológicas da costa, estendendo estas à porção subaquosa (BARLETTA, 2006; SPERANSKI e CALLIARI, 2006) e subaérea das praias arenosas (PEREIRA et al., 2010). A seguir, os dados sintetizados na Tabela 1 serão analisados por segmento de costa.

Tabela 1: Segmento de costa analisado em cada localidade, área de dunas erodidas e variação média da linha de costa atribuídas ao evento hidrodinâmico extremo.

\begin{tabular}{lccc}
\hline $\begin{array}{c}\text { Parâmetros } \\
\text { Localidades }\end{array}$ & $\begin{array}{c}\text { Segmento de costa } \\
\text { analisado }(\mathbf{m})\end{array}$ & $\begin{array}{c}\text { Área de dunas } \\
\text { erodida }\left(\mathbf{m}^{2}\right)\end{array}$ & $\begin{array}{c}\text { Variação da linha } \\
\text { de costa }(\mathbf{m})\end{array}$ \\
\hline MOSTARDENSE & 1975,00 & 27299,83 & 13,82 \\
\hline PRAIA DO FAROL & 722,52 & 15776,95 & 21,83 \\
\hline MAR GROSSO & 260,00 & 2501,39 & 9,62 \\
\hline CASSINO & 368,50 & 1497,04 & 4,06 \\
\hline HERMENEGILDO & 549,50 & 5464,75 & 9,94 \\
\hline MARAVILHAS & 363,00 & 3195,41 & 8,80 \\
\hline
\end{tabular}

\section{Impactos nos Balneários Mostardense e Praia do Farol de Mostardas}

Inicialmente foi realizada uma análise conjunta das duas localidades situadas mais ao norte da área de estudo: balneário Mostardense, município de Mostardas, e Praia do Farol, município de Tavares, situados num trecho de projeção costeira a oeste da Lagoa dos Patos.

Como efeito do ciclone no balneário Mostardense, ocorreu uma generalizada retração da base das dunas frontais (Tabela 1, Figura 6a), que já se apresentavam escarpadas por eventos de alta energia de onda anteriores. Em alguns segmentos a diferença entre as linhas vetorizadas antes e depois do evento de alta energia de onda analisado foi superior a $40 \mathrm{~m}$, sobretudo junto a algumas reentrâncias da costa, geradas por canais sangradouros e arruamentos. Aárea erodida foi superior a 27 mil m², tendo uma retração média da linha de costa de cerca de 13,82 m (Tabela 1, Figura 6a). Na Figura $6 \mathrm{~b}$ percebe-se uma trilha paralela as dunas frontais, que pode ser usada como indicador do processo erosivo. Este processo erosivo removeu esta porção de dunas frontais, observadas na Figura 6b, deixando as edificações mais próximas da praia (Figura 6c) e, portanto, mais vulneráveis a futuros processos erosivos.

No balneário Praia do Farol de Mostardas, o processo erosivo medido decorrente do ciclone foi maior que no balneário Mostardense, causando significativa retração das dunas frontais (Tabela 1, Figura 7a). No segmento de $700 \mathrm{~m}$ analisado foi perdida uma área superior a 15 mil $\mathrm{m}^{2}$ de dunas, com retração média da linha de costa de $21,83 \mathrm{~m}$. Observações in loco depois do evento identificaram que uma edificação de madeira foi deslocada para norte. A própria cerca do Farol de Mostardas, o que dá nome a localidade, também sofreu avarias, tendo que ser recolocada seguindo a nova linha de costa (Figura 7a). O processo de retração da costa não foi homogêneo, sendo maior onde existem duas reentrâncias, na porção norte da orla urbana, onde a variação superou os $30 \mathrm{~m}$. Esta reentrância é ocasionada pela presença de uma pequena rede de drenagem e por uma via de acesso à praia (Figura $7 b$ ), que fragmenta as dunas frontais, fato semelhante ao ocorrido no balneário Mostardense.

Conforme a Tabela 1, as maiores taxas de erosão das dunas frontais ocorreram na praia do Farol e no balneário Mostardense. Isso pode, pelo menos em parte, estar relacionado ao fato deste segmento, mais ao norte da área de estudo, estar situado num trecho de linha de costa marcada por projeções costeiras, linha de costa convexa em planta e praias com alta mobilidade sedimentar (BARLETTA, 2000; ABSALONSEM e TOLDO JR, 2007). Dillenburg et al., (2003), ao realizar perfis transversais a orientação da linha de costa entre +2 e -70 metros de profundidade em todo o Estado do Rio Grande do Sul, constataram que, onde a costa apresenta uma morfologia convexa em planta, como neste segmento entre Mostardense e Praia do Farol, a declividade da antepraia tende a ser maior. No local, a isóbata de 20 m é mais próxima da linha de costa que nos segmentos analisados mais a sul, expondo essa área de estudo a uma maior energia de ondas em relação aos setores côncavos. Barletta (2006) sustenta que existe uma relação entre a morfologia da antepraia e padrões de refração de ondas, os quais interferem sobre a distribuição de alturas e direções de ondas em grandes trechos da costa. Speranski e Calliari (2006) identificaram focos de energia de onda devido a refração. 


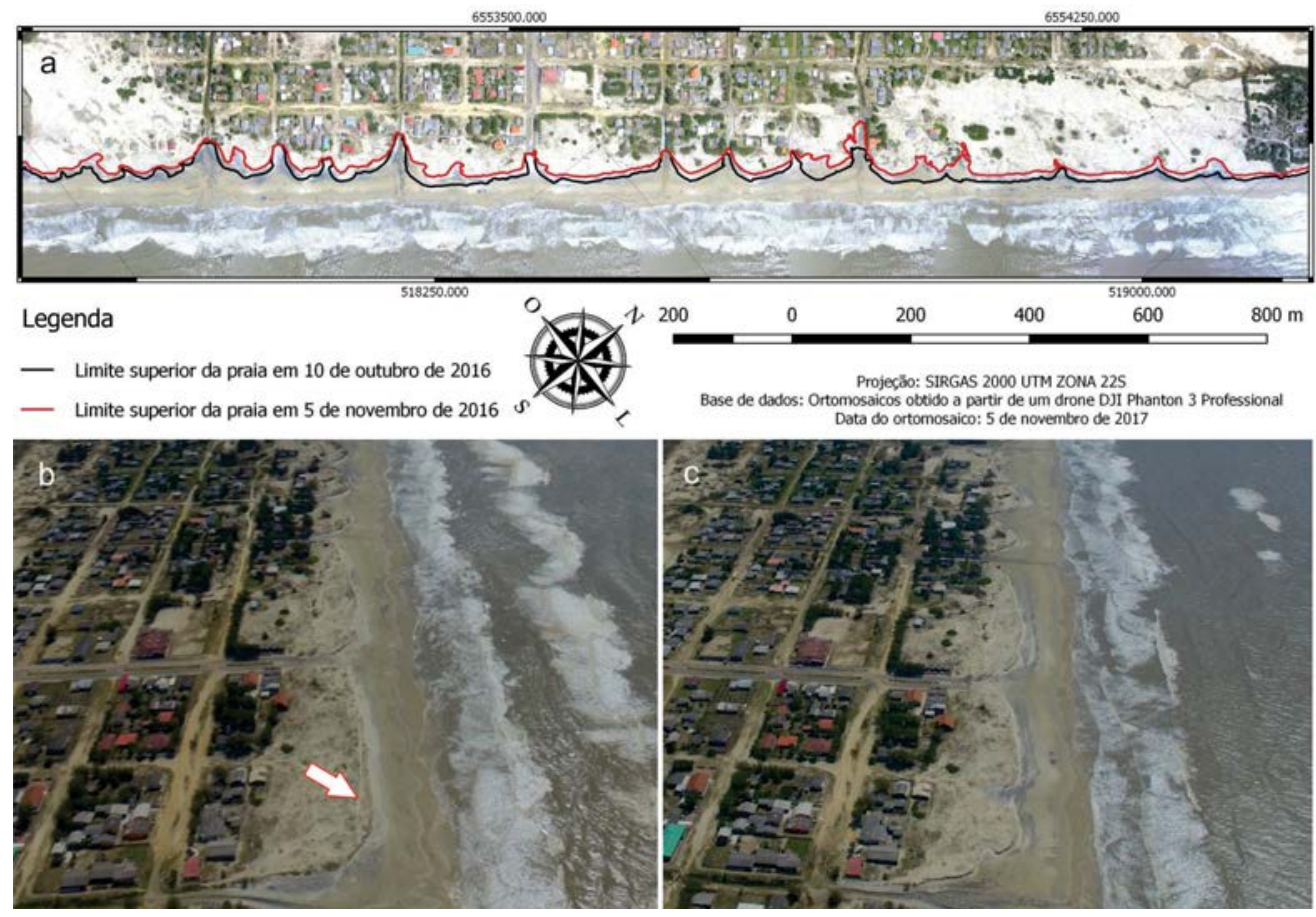

Figura 6 - a) Retração das dunas frontais entre 10/10/2016 e 05/11/2016 no balneário Mostardense. b) Fotografia aérea obliqua da orla do balneário obtida por um drone em 10/10/2016, antes do evento, destacando uma trilha de pessoas paralela as dunas e c) fotografia aérea obliqua da orla depois do evento, obtida pelo drone em 05/11/2016, já sem a presença da trilha indicada.
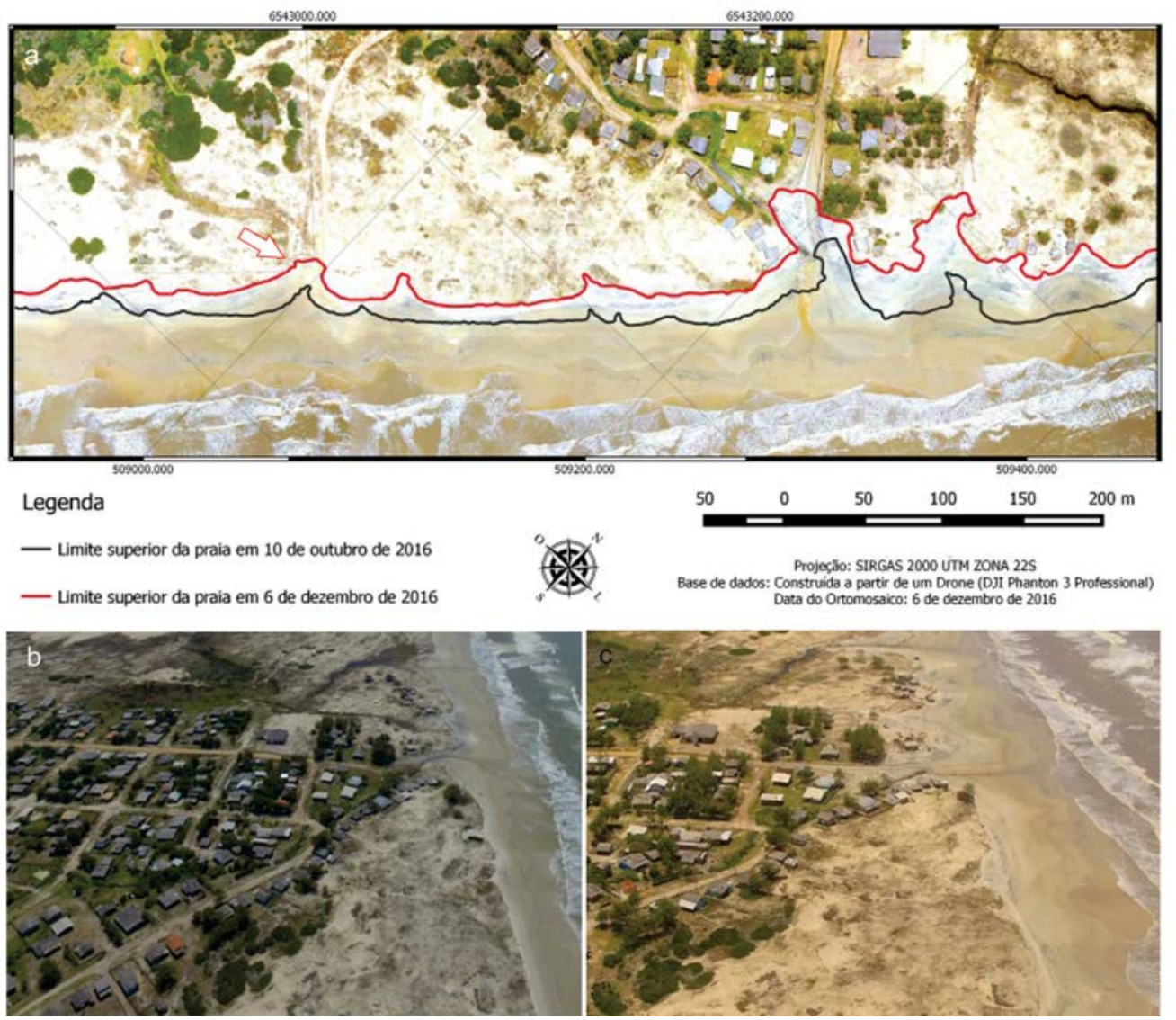

Figura 7 - a) Retração das dunas frontais entre 10/10/2016 e 06/12/2016 no balneário Praia do Farol. Neste mosaico de fotografias está destacada por uma seta, uma porção da cerca que delimita o Farol de Mostardas que foi recuada após ser danificada pelo evento. b) Fotografia aérea obliqua da orla do balneário obtida por um drone em 10/10/2016, antes do evento. c) Fotografia aérea obliqua da orla depois do evento, obtida pelo drone em 06/12/2016. 
Impactos nos Balneários Mar Grosso e Cassino

Os balneários do Mar Grosso, em São José do Norte, e do Cassino, em Rio Grande, estão situados nas adjacências da desembocadura da Lagoa dos Patos (Figura 1), maior estuário do sul do Brasil, também tiveram as dunas frontais erodidas pelo evento de alta energia de onda (Tabela 1). Nos $260 \mathrm{~m}$ de linha de costa analisados no balneário Mar Grosso (Figura 8) foi perdida uma área de dunas superior a $2500 \mathrm{~m}^{2}$, com retração média da linha de costa (limite praia-duna) superior a $9 \mathrm{~m}$.
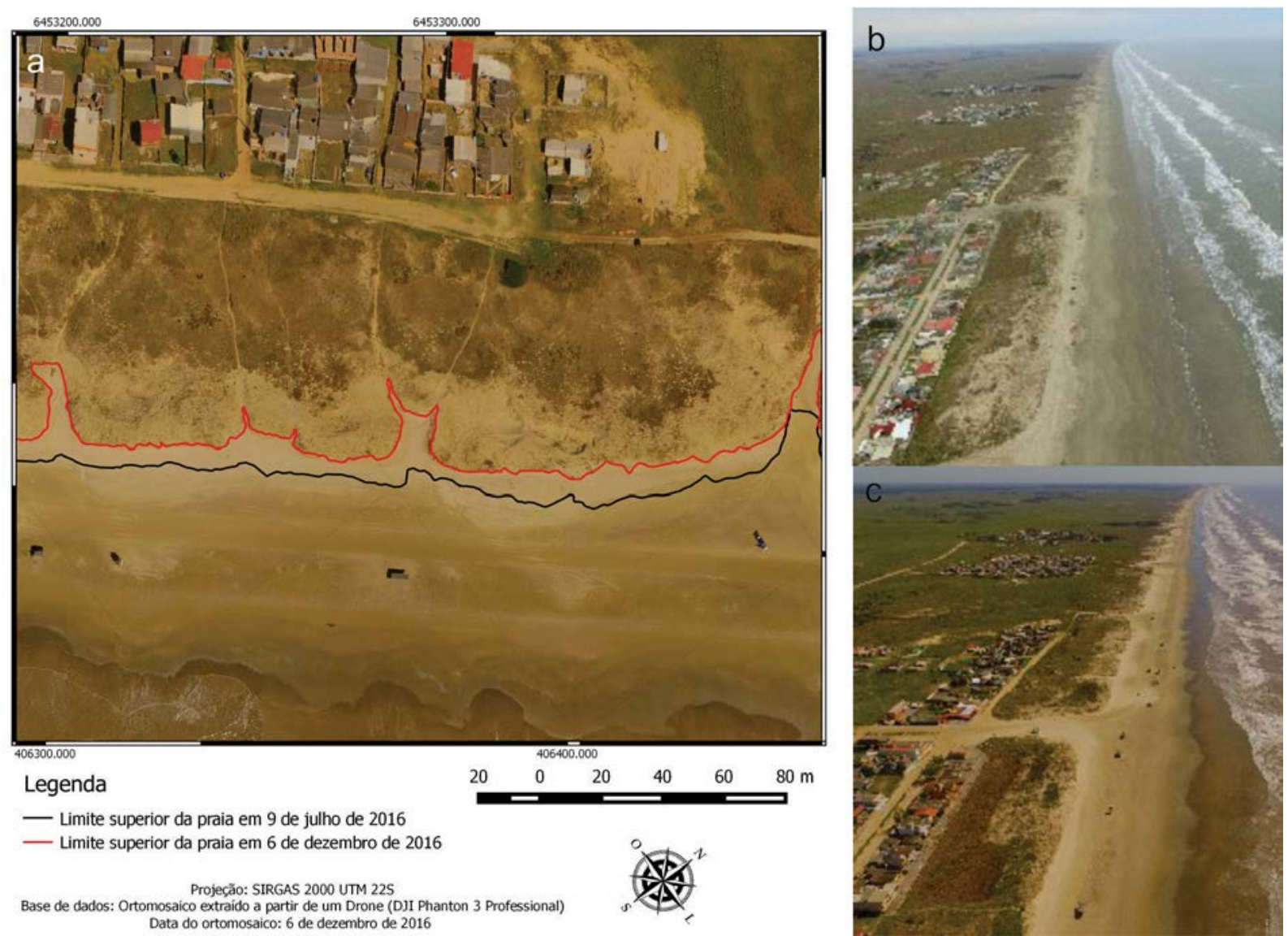

Figura 8 - a) Variação da linha de costa no balneário Mar Grosso entre 9/7/2016 e 6/12/2016, identificando a retração das dunas no período. b) Fotografia aérea obliqua em 9/7/2016, antes do evento de alta energia hidrodinâmico analisado. c) Fotografia do trecho em 6/12/2016, depois do evento analisado.

Já na praia do Cassino, no segmento de $368 \mathrm{~m}$ analisado, localizado próximo a área central do balneário, onde há uma passarela sobre as dunas (Figura 9), a área de dunas perdida foi de cerca de $1500 \mathrm{~m}^{2}$, com retração da costa de cerca de $4 \mathrm{~m}$, o menor valor dentre as áreas analisadas.

Na porção emersa destas localidades (Mar Grosso e Cassino), a barreira holocênica apresenta característica progradante (DILLENBURG et al., 2000), com variações morfológicas entre ambos. A plataforma continental é mais larga e com topografia suave (cerca de 0,03 graus) que nos trechos mais ao norte (Mostardense e
Farol), onde a topografia submarina é mais acentuada (cerca de 0,12 graus) e acidentada (BARLETTA, 2006). Na costa oceânica do Rio Grande do Sul, as áreas com plataforma continental mais larga e com gradiente suave ocorrem nos segmentos de linha de costa mais côncavos em planta, que apresentam menor energia de onda na costa (DILLENBURG et al., 2003), dada maior atenuação durante sua propagação rumo a águas rasas. Conforme a Tabela 1, os valores erosivos em Mar Grosso e Cassino foram inferiores aos de Mostardense e praia do Farol. 

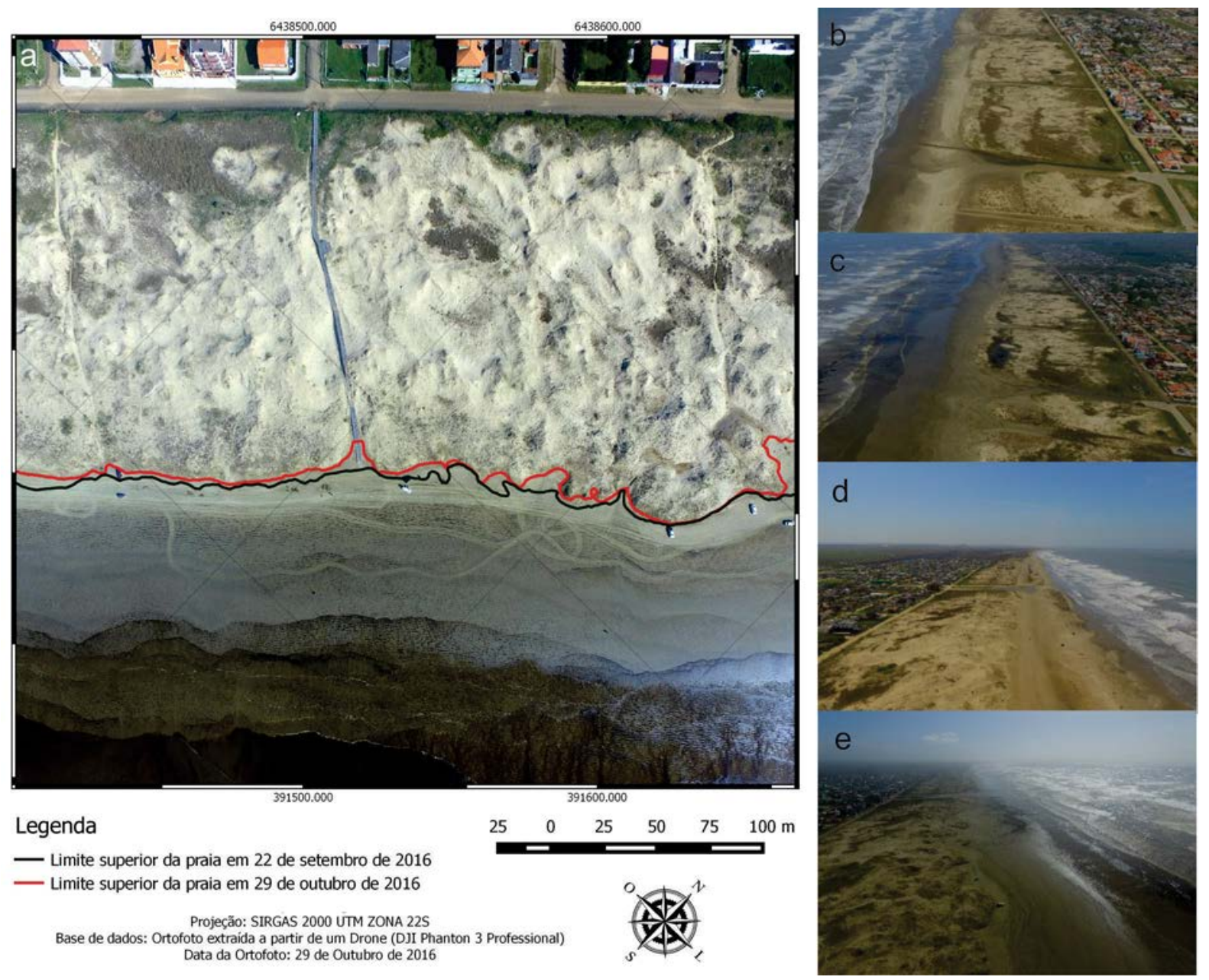

Figura 9 - a) Variação da linha de costa entre 22/09/2016 e 29/10/2016 no balneário Cassino, identificando a retração das dunas. b) Fotografia aérea obliqua antes do ciclone ao sul da área medida. c) Fotografia do trecho ao sul depois do ciclone, mostrando o aporte de material orgânico e inorgânico sobre as dunas frontais. d) Fotografia aérea obliqua antes do ciclone ao norte da área medida. e) Fotografia do trecho ao norte depois do ciclone, mostrando a exposição dos depósitos de lama e a erosão das dunas frontais.

Embora este trabalho analise na escala de eventos, por vezes é necessário trazer à tona trabalhos que indicam taxas de variação da costa, buscando compreender o comportamento da costa para inserir a escala de eventos no contexto. Na praia junto ao balneário do Mar Grosso as taxas de variação da linha de costa não indicam variações ora mais erosivas, ora mais acrescidas. Os primeiros dados encontrados em Mota (1969) mostram valores de acresção, enquanto que os de Long e Paim (1987) apontam erosão. Posteriormente, Lelis (2003) analisou $14 \mathrm{~km}$ da praia a partir da base do molhe leste da desembocadura da Lagoa dos Patos, para norte, onde se situa o balneário Mar Grosso, utilizando levantamentos aerofotogramétricos de 1974 e 2000. Os valores obtidos por Lelis (2003) e Lelis e Calliari (2004) apontam valores tanto erosivos quanto de acresção na linha de costa, entre as duas cenas analisadas, predominando valores erosivos, com maior erosão a cerca de 3 $\mathrm{km}$ dos molhes, e mais acresção um pouco distante dos molhes, próximo ao local onde se localiza o Mar Grosso, a partir de $10 \mathrm{~km}$ ao norte dos molhes da Barra. Simões (2015) analisou a variação entre o limite superior da praia e as edificações do balneário Mar Grosso entre 2006 e 2014, demonstrando mais acresção que erosão no limite praia duna, fato corroborado por Leal (2016), que analisou a variação do limite praia duna utilizando imagens orbitais de 2006, 2009, 2012, 2014 e 2015.

Já na praia junto ao balneário Cassino, significativas taxas de acresção da costa nos últimos anos vêm sendo demonstradas por alguns autores com destaque a Lelis (2003), Lelis e Calliari (2004), Goulart (2014), Porto (2016), Leal (2016). A desembocadura da Lagoa 
dos Patos é alterada pela construção de dois molhes que avançam mais de $4 \mathrm{~km}$ mar adentro e um canal de acesso atualmente com profundidades mais de 3 vezes superiores ao calado natural. Nos últimos anos, o segmento de orla analisado no Cassino tem recebido maiores volumes de depósitos de lama fluída provenientes da antepraia (MARTINS et al., 2003; CALLIARI et al., 2016b), sendo a origem destes sedimentos, o estuário da Lagoa dos Patos e/ou descartes de dragagens portuárias, e sua ocorrência na praia, fruto da ação de eventos de alta energia de onda, quando são depositados. Estes depósitos lamíticos atenuam a ação das ondas e deslocam a zona de arrebentação em direção offshore (GOULART, 2014), promovendo um aumento na largura da praia (PORTO, 2016; LEAL, 2016).

Todavia, embora Mar Grosso e Cassino tenham um comportamento relativamente estável da costa, dado o aporte sedimentar que têm, também estão susceptíveis a erosão costeira decorrente de eventos extremos (Figuras 8,9 ), mesmo que estes não ocorram com a mesma magnitude que em outros locais, como os descritos em Mostardense e Praia do Farol. Ainda assim, o evento analisado gerou erosão das dunas frontais nestes locais. A figura $5 \mathrm{c}$ demonstra uma pequena parcela da área urbana do Cassino, na retaguarda das extensas dunas frontais, inundada pelo mar. Ao sul da área analisada no Cassino é possível observar que o evento além de erodir as dunas, aportou sedimentos e matéria orgânica sobre a faixa de dunas (Figura 9b). Já ao norte da área analisada no Cassino ficou evidenciada a exposição de depósitos de lama e a erosão pontual das dunas frontais (Figura 9d). Provavelmente, nesta praia o maior impacto do ciclone talvez tenha sido na remobilização de sedimentos da antepraia e praia submersa, anteriormente recobertos por depósitos de lama fluída no trecho de costa medido, o que não foi analisado neste trabalho.

\section{Impactos nos Balneários Hermenegildo e Maravilhas}

Os balneários Hermenegildo e Maravilhas, situados no município de Santa Vitória do Palmar, no extremo sul da área de estudo, também sofreram erosão costeira decorrente deste evento extremo de alta energia de onda (Tabela 1).

O balneário do Hermenegildo, juntamente com o trecho de costa onde se localiza o Farol da Conceição, trecho não urbanizado situado entre São José do Norte e Tavares, são apontados como os dois segmentos com tendência mais erosiva da costa oceânica do Rio Grande do Sul (SPERANSKI; CALLIARI, 2006), dada a concentração de energia de onda, sendo os locais onde tem se diagnosticado as maiores taxas de erosão na costa. No balneário do Hermenegildo foram apresentadas taxas de retração da costa por vários autores, tais como de $0,5 \mathrm{~m} / \mathrm{ano}$ (TOZZI, 1999), de $4 \mathrm{~m} /$ ano (TOLDO JR et al., 2005) e de 1,68 m/ ano, com variações ao longo de 65 anos de análise (ALBUQUERQUE, 2013; ALBUQUERQUE et al., 2013). Ressalta-se que as taxas de variação apresentadas acima são derivadas de medições pontuais, provenientes de técnicas de cartografia digital e medições de campo, as quais são subdivididas por certo período, definindo taxas de erosão. No entanto, neste evento analisado (Tabela 1), o valor médio obtido no Hermenegildo foi menos da metade do valor obtido na praia do Farol de Mostardas e menor que no balneário Mostardense, locais analisados mais ao norte da área de estudo.

No segmento norte do balneário Hermenegildo (Figura 10), analisado neste estudo, ainda estão presentes dunas frontais, as quais vêm sendo erodidas nos últimos anos (KOERNER et al.; 2013; ALBUQUERQUE et al., 2013). Segundo Oliveira e Koerner (2015) a evolução do processo erosivo fez com que os moradores passassem a introduzir diversas estruturas de contenção, que atualmente representam $70 \%$ da orla urbana, também presentes no segmento norte do balneário. As estruturas de contenção que vêm se mostrando mais eficientes são as que se adaptam a mobilidade praial, como blocos de rocha (enrocamento) ou concreto (blocos pré-moldados de concreto) (OLIVEIRA e KOERNER, 2015), visto que estruturas mais rígidas, como muros, acabam colapsando por falta de sustentação na base. Tais contenções preservam as edificações, mas prejudicam a mobilidade do perfil dinâmico. Esta característica explica porque parte da orla urbana no balneário Hermenegildo encontra-se em projeção no pós-praia (KOERNER et al., 2013) (Figura 10a e 10b). Com isto, há presença de algumas estruturas de contenção no segmento analisado, mesmo que neste setor em específico ainda prevaleçam as dunas frontais.

O mosaico de fotografias aéreas dessa porção do balneário demonstra retração das dunas (Figura 10a). Nos cerca de $550 \mathrm{~m}$ de costa da porção norte do balneário a perda de área de dunas superou os $5400 \mathrm{~m}^{2}$, com retração média da costa superior a $9 \mathrm{~m}$, valor que poderia ser ainda maior, visto que em alguns segmentos 
medidos também há estruturas de contenção, embora em menor número do que nos segmentos central e sul do balneário. Nos trechos onde havia somente dunas, a variação foi maior que $10 \mathrm{~m}$, chegando a quase $20 \mathrm{~m}$ em alguns segmentos, valores próximos aos encontrados no balneário Mostardense, enquanto que nos trechos com estruturas de contenção a linha vetorizada antes e depois do evento tenha tido praticamente a mesma posição, dada maior resistência do enrocamento em relação aos depósitos eólicos à ação das ondas de tempestade.
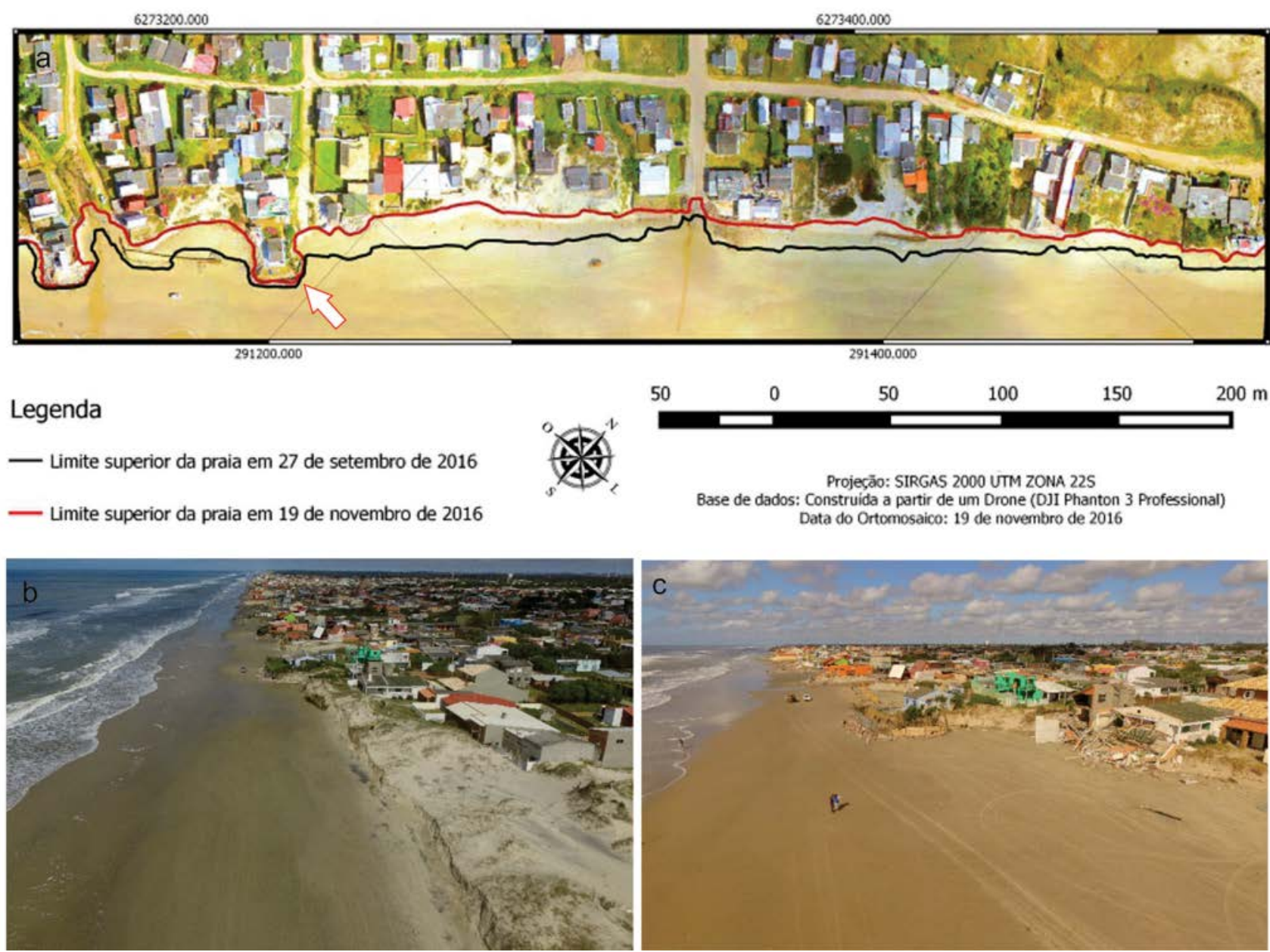

Figura 10 - a) Retração das dunas frontais entre 27/09/2017 e 19/11/2016 no balneário do Hermenegildo, destacando segmento com enrocamento, onde a retração foi menor. b) Fotografia aérea obliqua da orla do balneário obtida por um drone em 27/09/2017, antes do evento e c) Fotografia aérea obliqua da orla depois do evento, obtida por um drone em 19/11/2016, destacando o colapso de uma edificação pela ação marinha.

Desta forma, a taxa de erosão das dunas no balneário Hermenegildo tem, pelo menos em parte, relação com a presença das estruturas de contenção a erosão costeira, que podem ser identificadas nas linhas vetorizadas (Figura 10a). A Figura 10b mostra que no trecho ao norte, as dunas frontais estão escarpadas. Já a Figura 10c mostra casas danificadas pelo evento de alta energia de onda. O valor numérico médio obtido (Tabela 1), neste local foi influenciado por alguns segmentos com estruturas de contenção, que diminuíram o valor médio de erosão das dunas frontais.

Na localidade de Maravilhas, situada entre Hermenegildo e a Barra do Arroio Chuí, a Figura 11 demonstra o processo erosivo no local. Nos cerca de $360 \mathrm{~m}$ de costa analisado houve perda de dunas superior a $3000 \mathrm{~m}^{2}$, tendo retração média de costa de quase $9 \mathrm{~m}$, ultrapassando os $10 \mathrm{~m}$ em alguns trechos (Figura 11a). Duas edificações mais próximas da praia foram danificadas (Figura 11c). 


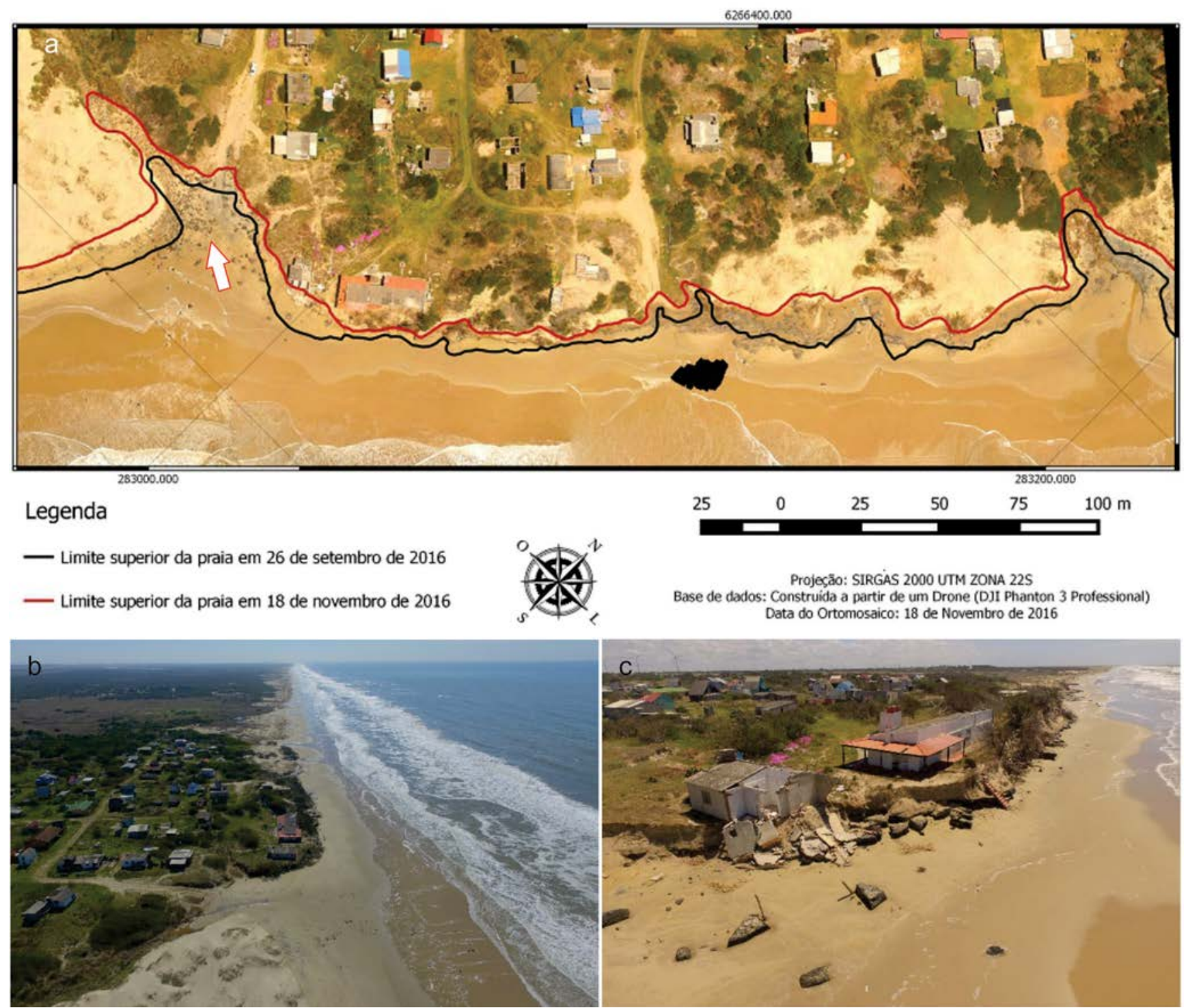

Figura 11 - a) Retração das dunas frontais entre 26/09/2016 e 18/11/2016 no balneário das Maravilhas, destacando reentrância com presença de fragmentos de turfa. b) Fotografia aérea obliqua da orla do balneário obtida por um drone em 26/09/2016, antes do evento. c) Fotografia aérea obliqua da orla depois do evento, obtida pelo drone em 18/11/2016, destacando o colapso de duas edificações pela ação marinha.

Na localidade de Maravilhas, afloram atualmente depósitos de lama consolidada e turfa (BUCHMANN et al., 1998). A presença de turfas acima do nível da praia, sob as dunas frontais, e de uma cobertura vegetal um pouco mais densa, podem ter, neste caso específico, minimizado a erosão das dunas no local. As dunas, por serem formadas por sedimentos, são mais suscetíveis à erosão do que os enrocamentos, como ocorre no Hermenegildo, ou mesmo as turfas. Segundo Brady e Weli (2013), solos orgânicos são altamente compressíveis ao cisalhamento, embora sua capacidade de sustentação seja muito baixa. A maior retração ocorreu nas adjacências da orla urbana, onde há reentrâncias (Figura 11a). Houve na maior reentrância, localizada logo a sul da área urbana, um avanço do mar por algumas dezenas de metros, carregando restos de depósitos turfáceos que, após desmoronarem, formaram pequenos blocos, conforme observado na Figura 11a com uma seta. Ressalta-se também a dificuldade de vetorizar o limite analisado neste segmento. Na Figura 11a, junto a maior reentrância destacada na referida figura, a linha vetorizada vermelha, que está sobre sua própria base cartográfica, parece não sincronizar com o limite praia duna. As fotografias aéreas oblíquas e as observações in loco possibilitaram identificar com precisão o limite praia duna definido para este trabalho, 
a base da escarpa da duna frontal. Neste mosaico, parte do limite superior da praia estava recoberto por areias secas dando a tonalidade mais clara. Este exemplo mostra a importância do uso de drone para análise da variação da linha de costa, pois tal fato dificilmente seria identificado a partir de imagens orbitais.

As diferenças erosivas encontradas na orla (limite praia duna) das seis localidades costeiras (balneários) analisadas neste trabalho podem ser um retrato da própria ação do evento, fato não analisado; das características geomorfológicas regionais (Figura 2), descritas anteriormente; mas também da existência de uma erosão diferencial, fruto da ocorrência de afloramentos diferenciados ao longo da costa, no caso deste estudo estruturas de contenção a erosão, destacando o enrocamento de origem antrópica da linha de costa, no balneário do Hermenegildo (Figuras 10b, 10c), e a presença de turfas, depósitos de origem natural, situadas na base das dunas frontais no balneário Praia de Maravilhas, fato que pode ser melhor observado na Figura 11c. A cobertura vegetal também pode ter tido alguma influência.

\section{Considerações Finais}

Este trabalho caracterizou uma significativa retração das dunas ocasionada por um evento extremo de alta energia de onda, ocorrido em 27 e 28 de outubro de 2016 em trechos da costa central e sul do Rio Grande do Sul, no extremo sul do Brasil, usando fotografias aéreas verticais e oblíquas de alta resolução capturadas por um drone. Este evento de alta energia de onda foi provavelmente o maior dos últimos 40 anos na costa oceânica do Rio Grande do Sul, com ondas de mais de $5 \mathrm{~m}$ próximas da costa. A severa erosão possivelmente se deu por uma conjunção de fatores, sobretudo pela ação das ondas e maré.

Este evento extremo de alta energia de onda causou erosão das dunas frontais em todas as seis localidades analisadas, variando de 4 a $21 \mathrm{~m}$ de erosão média da linha de costa, tendo alcançado $40 \mathrm{~m}$ em certos segmentos analisados. Houve variações nas taxas encontradas nos seis trechos analisados. As maiores taxas nas duas áreas mais ao norte devem-se tanto as características naturais do local quanto a ausência de ações humanas que pudessem interferir no processo erosivo, já que as dunas são mais sensíveis a erosão, visto que estas são constituídas basicamente por material inconsolidado. Nas áreas com barreira progradante e influência es- tuarina (Mar Grosso e Cassino) houve retração, mas também aporte de sedimentos para a praia, havendo mais inundação da orla do que propriamente erosão em relação às demais localidades analisadas. Provavelmente as taxas nos balneários mais ao sul (Hermenegildo e Maravilhas) não tenham sido maiores pela presença de estruturas mais resistentes junto à costa, estruturas de contenção a erosão no Hermenegildo (enrocamento) e turfas em Maravilhas, o que provavelmente contribuiu na redução da taxa de recuo médio das dunas frontais.

Eventos de alta energia de onda são frequentes na costa oceânica do Rio Grande do Sul. No entanto, processos erosivos intensos das dunas frontais não ocorrem com tanta frequência, sendo, em geral, fruto de eventos extremos de alta energia de onda. Nos locais analisados onde há histórico de erosão costeira, como no balneário Hermenegildo, provavelmente haverá pouca recomposição das dunas frontais, sendo este mais um evento erosivo no local, embora de grande magnitude. Já em outros locais com maior aporte sedimentar, como no balneário Cassino, pode haver maior recuperação das dunas frontais, cabendo a estudos futuros definir isso.

A descrição deste processo erosivo intenso é importante para o planejamento da ocupação costeira no sentido de identificar que a variação (erosão) da linha de costa (no caso o limite entre a praia e a duna frontal) não é um processo linear, muitas vezes sendo uma resposta a eventos de alta energia de onda, sobretudo os chamados eventos extremos. Assim, novas ocupações costeiras devem manter-se afastadas da linha de costa, mesmo em locais com maior aporte sedimentar, pois a proximidade com o oceano em uma costa arenosa, com certa mobilidade sedimentar e relativamente plana, poderá implicar no futuro, em problemas socioambientais como os já enfrentados no balneário do Hermenegildo, e que se encontram em estágios iniciais nos balneários Mostardense, Praia do Farol e Maravilhas. Este fato foi agravado pela perda da zona de amortecimento (dunas frontais) e de patrimônio edificado, após a passagem do ciclone de outubro de 2016.

Por fim, este trabalho também identificou que as variações geomorfológicas regionais e locais, as variações morfodinâmicas e a resistência dos materiais, somadas as próprias características do evento junto à costa, são distintas, tornando um desafio prever com exatidão o deslocamento da linha de costa por modelos mais genéricos. 
Agradecimentos: Ao CNPq Edital Universal pelo financiamento do Projeto no qual este trabalho se inseriu (Edital Universal 2014-3, processo 446963/2014-3) e por conceder bolsas PBIC. A CAPES pela concessão de bolsa de mestrado, Processo 001. Ao Laboratório de Monitoramento da Criosfera (Lacrio-FURG) e ao Grupo de Pesquisas Geotecnologias e Meio Ambiente GEOMA - IFRS por emprestarem os softwares ArcGis e Agisoft Photoscan respectivamente. Ao Professor Elói Melo e a Praticagem do Porto do Rio Grande pelos dados de maré medida. A este Professor também agradecemos pela inspiração à estudos desta natureza.

\section{Referências Bibliográficas}

ABSALONSEN, L.; TOLDO JR., E. A Influência da Inflexão Costeira na Variabilidade da Linha de Praia em Mostardas - RS. Revista Pesquisas em Geociências, v.34, p.3-18, 2007.

ALBUQUERQUE, M.G. Análise espaço-temporal das causas da variabilidade da linha de costa e erosão na praia do Hermenegildo - RS. Tese (Doutorado em Geociências). Instituto de Geociências. Universidade Federal do Rio Grande do Sul, Porto Alegre. 2013. 127p.

ALBUQUERQUE, M.G.; ESPINOZA, J.M.A.; OLIVEIRA, A.; CORREAA, I.; CALLIARI, L.J. Erosion or Coastal Variability: an evaluation of the DSAS and the Change Polygon methods for the determination of erosive processes on sandy beaches. Journal of Coastal Research, v.65, p.1710-1714, 2013.

BARLETTA, R. C. Efeito da interação oceano-atmosfera sobre a morfodinâmica das praias do litoral central do Rio Grande do Rio Grande do Sul, Brasil. Dissertação (Mestrado em Oceanografia Física, Química e Geológica). Universidade Federal Rio Grande, Rio Grande. 2000.

BARLETTA, R.C.; CALLIARI, L.J. Determinação da intensidade das tempestades que atuam no litoral do Rio Grande do Sul, Brasil. Porto alegre: Pesquisas em Geociências, v.28(2), p.117-124, 2002.

BARLETTA, R.C. Teste e aplicação de modelos parabólicos de refração-difração com ênfase na propagação de ondas sobre parcéis. Tese (Doutorado em Engenharia Ambiental). Universidade Federal de Santa Catarina, Florianópolis. 2006. $155 \mathrm{p}$.

BOAK, E.H.; TURNER, I.L. Shoreline Definition and Detection: A Review. Florida. Journal of Coastal Research v.21, p.688703, 2005.
BRADY, N.C. E WELI, R.R. Elementos da natureza e propriedades dos solos. $3^{\mathrm{a}}$ edição Bookman. 2013.

BRASIL, 2004. Decreto $\mathbf{n}^{\mathbf{0}}$ 5.300, de 7de dezembro de 2004 . Regulamenta a Lei $n^{\circ} 7.661$, de 16 de maio de 1988, que institui o Plano Nacional de Gerenciamento Costeiro (PNGC), dispõe sobre regras de uso e ocupação da zona costeira, estabelece critérios de gestão da orla marítima, e dá outras providências. $<$ www.planalto.gov.br $>$

BUCHMANN, F. S. C.; BARBOSA, V. P.; VILLWOCK, J. A. Sedimentologia e paleoecologia durante o máximo transgressivo holocênico na Lagoa Mirim, RS, Brasil. Acta Geológica Leopoldensia, v.46/47, p.21-26, 1998.

CALLIARI, L.J.; KLEIN, A.H.F. Características morfodinâmicas e sedimentológicas das praias oceânicas entre Rio Grande e Chuí, RS. Porto Alegre: Revista Pesquisas em Geociências, v.20, p.48-56, 1993.

CALliARI, L.J., TOZZI, H., KLEIN, A. (1999). Beach morphology and coastline erosion associated with storm surges in southern Brazil - Rio Grande to Chui. RS. In: Land and Ocean Interaction in Coastal Zone (LOICZ) Meeting, São Paulo, p. 231-247.

CAlliari, L., PEREIRA, A.O., OliveirA, S.A., FIGUEIREDO. Variabilidade das dunas frontais no litoral norte $\mathrm{e}$ médio do Rio Grande do Sul, Brasil. Gravel, v.3, p.15-30, 2005.

CALLIARI, L.J.; TOLDO JR, E.E. (2016) Ocean Beaches of Rio Grande do Sul. In: SHORT, A.D.; KLEIN, A.H.F. (org.) Brazilian Beach Systems. Springer: Florida, p. 1-36.

CALLIARI, L.; MACHADO, A.; MARROIG, P.; VINZON, S.; GIANUCA, N. Mud deposits at Cassino Beach: natural versus antrophic. Anais. PIANC-COPEDEC IX, Rio de Janeiro, Brasil. 2016.

CARON, L. Estratigrafia e evolução da barreira Holocênica na região costeira de Santa Vitória do Palmar, Planície Costeira do Rio Grande do Sul, Brasil. Tese (Doutorado em Geociências). Instituto de Geociências, Universidade Federal do Rio Grande do Sul. Porto Alegre. 2014. 127p.

COMPANHIA ESTADUAL DE ENERGIA ELÉTRICA (CEEE). Relatório 2016 - 021 de evento que tenha gerado interrupção em situação de emergência. 27 e 28 de outubro de 2016.

COSTA, D.C. Considerações sobre a evolução morfológica das dunas frontais ao balneário Cassino - RS a partir da implantação de ações de manejo. Trabalho de conclusão de curso (Graduação em Geografia Bacharelado). Instituto de 
Ciências Humanas e da Informação. Universidade Federal do Rio Grande, Rio Grande. 2014. 37p.

CUNHA. J.V. Descrição de ações de manejo ocorridas entre 2005 e 2011 e seus reflexos no crescimento de dunas frontais no balneário do Mar Grosso, São José do Norte, RS. Trabalho de conclusão de curso (Graduação em Geografia Bacharelado). Instituto de Ciências Humanas e da Informação. Universidade Federal do Rio Grande, Rio Grande. 2013. 36p

DILLENBURG, S.R.; ROY, P.S.; COWELL, P.J.; TOMAZELLI, L.J. Influence to antecedent topography on coastal evolution as Testes by the Shoreface Translation Model (STM). Journal of Coastal Researsh, v.16(1), p.71-81, 2000.

DILLENBURG S.R.; TOMAZELLI L.J.; CLEROT L.C.P. Gradientes de energia de onda: o principal fator controlador da evolução costeira no Rio Grande do Sul durante o Holoceno Superior. Anais. II Congresso sobre Planejamento e Gestão das Zonas Costeiras dos Países de Expressão Portuguesa; IX Congresso da Associação Brasileira de Estudos do Quaternário; II Congresso do Quaternário dos Países de Língua Ibéricas. 2003.

DILLENBURG, S.R.; TOMAZELLI, L.J.; MARTINS, L.R.; BARBOZA, E.G. Modificações de Longo Período da Linha de Costa das Barreiras Costeiras do Rio Grande do Sul. Gravel. v.3, p.9-14, 2005.

DILLENBURG, S.R.; BARBOZA, E.G.; TOMAZELLI, L.J.; HESP, P.A.; CLEROT, L.C.P; AYUP-ZOUAIN, R.N. (2009). The Holocene Coastal Barriers of Rio Grande do Sul. In: DILlENBURG, S.R.; HESP, P.A. (Ed.). Geology and Geomorphology of Holocene Coastal Barriers of Brazil. Springer, Berlin: p. 53-91.

DOLAN. R.; DAVIS. R.E. An intensity scale for Atlantic coast northeast storms. Journal of Coastal Researsh. v.8(3), p.840853, 1992.

ESTEVES, L.S.; PIVEL, M.A.G.; SILVA, A.R.P.; BARLETTA, R.C.; VRANJAC, M.C.; OLIVEIRA, U.R.; VANZ, A. Beachfront Owners Perception of Beach Erosion along an Armored Shoreline in Southern Brazil. Porto Alegre: Revista Pesquisas em Geociências, v.27, p.93-109, 2000.

ESTEVES, L.S. Variabilidade espaço-temporal dos deslocamentos da linha de costa no Rio Grande do Sul. Tese (Doutorado em Geociências). Instituto de Geociências. Universidade Federal do Rio Grande do Sul, Porto Alegre. 2004. 150p.

GOULART, E.S. Variabilidade morfodinâmica temporal e eventos de inundação em um sistema praial com múltiplos bancos. Tese (Doutorado em Oceanografia Química, Física e
Geológica). Instituto de Oceanografia. Universidade Federal do Rio Grande, Rio Grande. 2014. 143p.

KOERNER, K. F. Variação espaço-temporal em médio e curto termo da orla do balneário do Hermenegildo, RS. Trabalho de conclusão de curso (Graduação em Oceanologia). Instituto de Oceanografia. Universidade Federal do Rio Grande, Rio Grande. 2009. 63p.

KOERNER, K.F.; OLIVEIRA, U.R.; GONÇALVES, G. Efeito de estruturas de Grande do Sul, Brasil. Revista Gestão Costeira Integrada, v.13, p.457-471, 2013.

IPCC. Climate Change 2007: Synthesis Report. Contribution of Working Groups I, II and III to the Fourth Assessment Report of the Intergovernamental Painel on Climate Change [Core Writing Team, Pachauri, R.K and Reisinger, A. (Eds.)]. IPCC, Geneva, Switzerland, 2007. 104p.

LEAL, K.B. Análise da variação da linha de costa nos balneários Mostardense, Mar Grosso, Cassino e Barra do Chuí - RS a partir de geotecnologias. Trabalho de conclusão de curso (Graduação em Geografia Bacharelado). Instituto de Ciências Humanas e da Informação. Universidade Federal do Rio Grande, Rio Grande. 2016. 90p.

LÉLIS, R. J. F. Variabilidade da linha de costa oceânica adjacente às principais desembocaduras do Rio Grande do Sul. Trabalho de conclusão de curso (Graduação em Oceanologia). Instituto de Oceanografia. Universidade Federal do Rio Grande, Rio Grande. 2003. 79p.

LÉLIS, R.J.F.; CALLIARI, L.J. Historical shoreline changes near lagoonal and river stabilized inlets in Rio Grande do Sul State, southern Brazil. Journal of Coastal Research, v.SI (39), p.301-305, 2004.

LIMA, L.G. Estratigrafia e Evolução da Barreira Holocênica na Praia do Hermenegildo, RS. Dissertação (Mestrado em Geociências). Instituto de Geociências. Universidade Federal do Rio Grande do Sul, Porto Alegre. 2008. 78p.

MACHADO, A.A.; CALLIARI, L.J.; MELO, E.; KLEIN, A.H.F. Historical assessment of extreme coastal sea state conditions in southern Brazil and their relation to erosion episodes. PanAmerican Journal of Aquatic Sciences, v.5(2), p.105-114, 2010 .

MARTINS, L.R.; TABAJARA, L.L.; FERREIRA, E.R. Linha de Costa: problemas e estudos. Porto Alegre: Gravel, v.2, p.4056, 2004.

MARTINS, L.R. MARTINS, I.R. TABAJARA, L.L. Ocorrência de fragmentos de lama na praia do Cassino, RS. Porto Alegre: 
Gravel v.1, p.47-53, 2003.

MELO, E.; MACHADO, D.M; LISBOA, R.C.; ROMEU, M.A.R. Overview of tide, wind and wave conditions along the Brazilian coast for coastal engineering practice. In: IX PIANCCOPEDEC, 9, 2016, Rio de Janeiro. Anais... 18p.

MILANA, J.P., GUEDES, C.C.F., BUSO, V.V. The coastal ridge sequence at Rio Grande do Sul: A new geoarchive for past climate events of the Atlantic coast of southern Brazil since the mid Holocene. Quaternary International. http://dx.doi. org/10.1016/j.quaint.2016.11.029. p. 1-13, 2016.

MORAES, A.C.R. Contribuições para a gestão da zona costeira do Brasil: elementos para uma geografia do litoral brasileiro. São Paulo: Annablume, 2007. 232p.

MOTA, V.F. Relatório-diagnóstico sobre a melhoria e o aprofundamento do acesso pela barra de Rio Grande. Instituto de Pesquisas Hidráulicas, Porto Alegre, RS. 1969. 144p.

MUEHE, D. Estado morfodinâmico praial no instante da observação: uma alternativa de identificação. Revista Brasileira de Oceanografia, v.46(2), p.157-169, 1998.

MUEHE, D. Definição de limites e tipologias da orla sob os aspectos morfodinâmico e evolutivo. In: Projeto Orla: subsídios de um projeto de gestão. Ministério do Meio Ambiente. pp. 11-30, 2001.

MUEHE, D. Definição de limites e tipologias de orlas sob os aspectos morfodinâmico e evolutivo. In: Ministério Do Meio Ambiente, Ministério Do Planejamento, Orçamento E Gestão. Projeto Orla: Subsídios para um projeto de gestão. Brasília, 101 p. 2004.

MUEHE, D.; LINS-DE-BARROS, F.; OLIVEIRA, J,F.; KLUMBOLIVEIRA, L. Pulsos erosivos e resposta morfodinâmica associada a eventos extremos na costa leste do Estado do Rio de Janeiro. Revista Brasileira de Geomorfologia, v.16(3), p.369-386, 2015.

OLIVEIRA, U.R.; KOERNER, K.F. Comportamento das estruturas de contenção à erosão costeira no balneário Hermenegildo. Ponta Grossa: Revista de Engenharia e Tecnologia, v.7, p.67-76, 2015.

OLIVEIRA, U.R.; KOERNER, K.F.; SIMÕES, R.S.; MOTA, G.S.; LEAL, K.B.; GAUTÉRIO, B.C. Histórico de antropização e supressão das dunas no balneário Hermenegildo, Rio Grande do Sul, Brasil. Revista Brasileira de Geografia Física v.11(2), p.687-704, 2018.

PEREIRA DA SILVA, R. Ocorrência, distribuição e características morfodinâmicas dos sangradouros na zona costeira do Rio Grande do Sul: trecho Rio Grande - Chuí, RS. Dissertação (Mestrado em Geociências). Universidade Federal do Rio Grande do Sul, Porto Alegre. 146p. 1998.

PEREIRA, P.S. Variabilidade da orla oceânica do Rio Grande do Sul e suas implicações na elaboração de planos de contingência: aspectos morfodinâmicos, sedimentológicos e geomorfológicos. Dissertação (Programa de Pós-graduação em Oceanografia Física, Química e Geológica). Universidade Federal do Rio Grande, 2005. 161p.

PEREIRA, P.S.; CALliARI, L.J.; BARLETTA, R.C. Heterogeneity and homogeneity of Southern Brazilian beaches: A morphodynamic and statistical approach. Continental Shelf Research, v.30, p.270-280, 2010.

PORTO, F.S. Variabilidade morfossedimentar do sistema praia duna ao largo do balneário Cassino - RS no período de 2006 a 2016. Dissertação (Mestrado em Geografia). Instituto de Ciências Humanas e da Informação. Universidade Federal do Rio Grande. 2016. 98p.

ROSA, M.L.C.C.; BARBOZA, E.G.; ABREU, V.S.; TOMAZELLI, L.J.; DILLENBURG, S.R., High-Frequency Sequences in the Quaternary of Pelotas Basin (coastal plain): a record of degradational stacking as a function of longer-term base-level fall. Brazilian Journal of Geology, v.47(2), p.183$207,2017$.

SIMÕES, R.S. Análise da distância média entre as ocupações à beira-mar e o limite superior da praia nos balneários São Simão, Mostardense, Praia do Farol e Mar Grosso, RS. Trabalho de conclusão de curso (Graduação em Geografia Licenciatura). Instituto de Ciências Humanas e da Informação. Universidade Federal do Rio Grande, Rio Grande. 2015. 84p.

SIMÕES, R.S. Mobilidade do limite praia duna no balneário Mostardense - RS: monitoramento por drone. Dissertação (Mestrado em Geografia). Instituto de Ciências Humanas e da Informação. Universidade Federal do Rio Grande. 2018. 128p.

SHORT, A.D. Beaches. 1999, in: SHORT, A.D. (Org.), Handbook of beach and shoreface morphodynamics. Jonh Wiley \& Sons, 1999. pp. 3-20.

SMITH, M.J.; CROWLEY, R.G. Measuring historical coastal change using GIS and the change polygon approach. Transaction in GIS, v.16(1), p.3-15, 2012.

SOUZA, C.R.G.; SOUZA FILHO, P.W.M.; ESTEVES, L.S.; VITAL, H.; DILLENBURG, S.R.; PATCHINEELAM, S.M.; ADDAD, J.E. Praias arenosas e erosão costeira. In: SOUZA, C.R.G., SUGUIO, K., OLIVEIRA, A.M.S., OLIVEIRA, P.E., (Eds.). Quaternário no Brasil. Holos Editora, pp. 130-152, 2005. 
SPERANSKI N.S.; CALLIARI, L.J. (2006). Rio Grande do Sul. In: MUEHE, D. (Org.) Erosão e Progradação do Litoral Brasileiro. Ministério do Meio Ambiente: p. 446-454.

STROAHECKER, T.M. A urbanização no litoral norte do Rio Grande do Sul: contribuição para a gestão urbana ambiental do município de capão da canoa. Tese (Doutorado em Geociências). Instituto de Geociências. Universidade Federal do Rio Grande do Sul, Porto Alegre. 2007. 399p.

TOZZI, H.A.M. 1999. Influência das Tempestades Extratropicais sobre o estoque subaéreo das praias entre Rio Grande e Chuí, RS. Dissertação (Mestrado em Geociências). Instituto de Geociências. Universidade Federal do Rio Grande do Sul, Porto Alegre. 1999. 115p.

TOLDO JR., E.; ALMEIDA, L.E.S.B.; NICOLODI, J.L.; MARTINS, L.R. Retração e progradação da zona costeira do estado do Rio Grande do Sul. Gravel, v.3(1), p.31-38, 2005.

TOLDO JR, E. E.; ALMEIDA, L.E. S. B.; NICOLODI, J.L.; ABSALONSEN, L.; GRUBER, N.L.S. O Controle da Deriva
Litorânea no Desenvolvimento do Campo de Dunas e da Antepraia no Litoral Médio do Rio Grande do Sul. Porto Alegre: Revista Pesquisas em Geociências, v.33, p.35-42, 2006.

UGRI, A. Mudanças em escala histórica das dunas costeiras do extremo sul do Brasil. Dissertação (Mestrado em Oceanografia Biológica). Universidade Federal do Rio Grande. 2004. 86p.

VIANNA, H.D. Sistema Praia Dunas Frontais, Variabilidade Sedimentológica, Morfológica e Suscetibilidade à Inundação no Litoral Norte do Rio Grande Do Sul, Brasil. Tese (Doutorado em Oceanografia Química, Física e Geológica). Instituto de Oceanografia. Universidade Federal do Rio Grande, Rio Grande. 2018. 172p.

VILLWOCK, J.A.; TOMAZELLI, L.J. Geologia costeira da Província costeira do Rio Grande do Sul. Porto Alegre: Notas Técnicas, v.8, p.1-45, 1995.

WRIGHT, L.D.; SHORT. A.D. Morphodynamic variability of surf zones and beaches: a synthesis. Amsterdam: Marine Geology. v.56, p.93-118, 1984. 